\title{
Metabolite Profile of Xylem Sap in Cotton Seedlings Is Changed by $\mathrm{K}$ Deficiency
}

\author{
Xin Zhang ${ }^{1}$, Guo Wang ${ }^{1}$, Huiyun Xue ${ }^{1}$, Jinbao Zhang ${ }^{1}$, Qinglian Wang ${ }^{1}$, Zhiyong Zhang ${ }^{1 *}$ \\ and Baohong Zhang ${ }^{2 *}$
}

${ }^{1}$ Henan Collaborative Innovation Centre of Modern Biological Breeding, Henan Institute of Science and Technology, Xinxiang, China, ${ }^{2}$ Department of Biology, East Carolina University, Greenville, NC, United States

\section{OPEN ACCESS}

Edited by:

Zhi-Yan (Rock) Du,

University of Hawai'i at Mānoa,

United States

Reviewed by:

Shahbaz Atta Tung,

University of Agriculture, Pakistan

Youhua Wang,

Nanjing Agricultural University, China

*Correspondence: Zhiyong Zhang

z_zy123@126.com

Baohong Zhang

zhangb@ecu.edu

Specialty section:

This article was submitted to

Plant Metabolism

and Chemodiversity,

a section of the journal

Frontiers in Plant Science

Received: 07 August 2020

Accepted: 14 October 2020

Published: 10 December 2020

Citation:

Zhang $X$, Wang $G$, Xue $H$,

Zhang J, Wang Q, Zhang Z and Zhang B (2020) Metabolite Profile of Xylem Sap in Cotton Seedlings Is

Changed by K Deficiency.

Front. Plant Sci. 11:592591.

doi: 10.3389/fpls.2020.592591
Xylem sap, belonging to the plant apoplast, not only provides plant tissues with inorganic and organic substances but also facilitates communication between the roots and the leaves and coordinates their development. This study investigated the effects of potassium $(\mathrm{K})$ deficiency on the morphology and the physiology of cotton seedlings as well as $\mathrm{pH}$, mineral nutrient contents, and metabolites of xylem sap. In particular, we compared changes in root-shoot communication under low $\mathrm{K}(\mathrm{LK})$ and normal $\mathrm{K}$ (NK, control) levels. Compared to control, LK stress significantly decreased seedling biomass (leaf, stem, and root dry weight; stem and root length; root surface area and root volume) and the levels of $\mathrm{K}, \mathrm{Na}$ (sodium), Mg (magnesium), Fe (iron), and Zn (zinc) in xylem sap. A total of 82 metabolites in sap analyzed by high-performance liquid chromatographytandem mass spectrometry (HPLC-MS/MS) showed significant differences between the two conditions; among these, 38 were up-regulated more than 2-fold, while the others were down-regulated less than 0.5 -fold. In particular, several metabolites found in the cell membrane including three cholines (glycerophosphatecholine, 2-hexenylcholine, and caproylcholine) and desglucocoroloside and others such as malondialdehyde, $\alpha$ amino acids and derivatives, sucrose, and sugar alcohol significantly increased under LK stress, indicating that cell membranes were damaged and protein metabolism was abnormal. It is worth noting that glycerophosphocholine was up-regulated 29-fold under LK stress, indicating that it can be used as an important signal of root-shoot communication. Furthermore, in pathway analyses, 26 metabolites were matched to Kyoto Encyclopedia of Genes and Genomes (KEGG) pathways; L-aspartic acid, which was associated with 10 KEGG pathways, was the most involved metabolite. Overall, K deficiency reduced the antioxidant capacity of cotton seedlings and led to a metabolic disorder including elevated levels of primary metabolites and inhibited production of secondary metabolites. This eventually resulted in decreased biomass of cotton seedlings under LK stress. This study lays a solid foundation for further research on targeted metabolites and signal substances in the xylem sap of cotton plants exposed to $\mathrm{K}$ deficiency.

Keywords: metabolite, cotton, xylem sap, potassium, deficiency 


\section{HIGHLIGHTS}

- Elaborated the morphology, physiological characteristics, and metabolites of xylem sap altered by potassium (K) deficiency in cotton.

- First report of the metabolome changes of xylem sap in cotton seedlings under $\mathrm{K}$ deficiency.

- K deficiency increased the contents of primary metabolites and inhibited the production of secondary metabolites.

\section{INTRODUCTION}

Potassium $(\mathrm{K})$ is a macronutrient, and unlike nitrate, phosphate, and sulfate, it is not assimilated into organic matter. It rather plays important roles in plant cells (e.g., expansion, turgor pressure, and osmo-regulation) and is involved in metabolism, growth, yield, and the opening and the closing of stomata in response to abiotic and biotic stresses (Hasanuzzaman et al., 2018; Chérel and Gaillard, 2019). K is involved directly or indirectly in plant protein and sugar metabolism (Chen et al., 2018; Andrea et al., 2020) and is required by more than 60 enzymes as a cofactor (Hawkesford et al., 2012; Vašák and Schnabl, 2016). Its levels affect those of primary and secondary metabolites in plants (Armengaud et al., 2009; Coskun et al., 2017; Chatterjee et al., 2020).

$\mathrm{K}$ deficiency is a common abiotic stress in agricultural production (Hosseini et al., 2017; Xu et al., 2020). It can lead to increases in the concentrations of free sugars in the leaves of bean (Cakmak et al., 1994), cotton (Bednarz and Oosterhuis, 1999; Pettigrew, 1999; Hu et al., 2017), potato (Koch et al., 2018), and oilseed rape (Pan et al., 2017), the roots of alfalfa (Jungers et al., 2019), rice (Ma et al., 2012; Chen et al., 2015), and sugar beet (Aksu and Altay, 2020), and the leaves and the roots of Arabidopsis (Armengaud et al., 2009), barley (Zeng et al., 2018), and tomato (Sung et al., 2015). In addition, excessive accumulation of free amino acids, especially proline, has been reported for tobacco (Ren et al., 2016), cotton (Hu et al., 2017), oilseed rape (Lu et al., 2019), barley (Zeng et al., 2018), and Arabidopsis (Armengaud et al., 2009). Significant changes in the metabolite profile of plants induced by K deficiency can lead to metabolism disorders (Hu et al., 2016).

Metabolomics (also known as metabonomics or metabolic profiling) is an emerging branch of "omics" research concerned with the comprehensive identification and quantification of small metabolites (molecular weight $<1 \mathrm{kDa}$ ) in organisms. Metabolites are the downstream products of numerous proteome-wide interactions, and non-targeted quantitative analyses of such metabolites in bio-fluids and tissues can be a very sensitive measure of an organism's phenotype (Hong et al., 2016). Hence, metabolomics can be particularly useful for identifying metabolic components contributing the most to key phenotypic and physiological traits (Thomason et al., 2018), studying environment-gene interactions (Ronny et al., 2013), and identifying disease or stress biomarkers (Peng et al., 2015).
Liquid chromatography-electrospray ionization-mass spectrometry (LC-ESI-MS) is a highly sensitive technique that provides information on the molecular masses of compounds. To obtain further structural information on the fragmentation patterns of compounds, ESI-tandem mass spectrometry (MS/MS) can be used (Mari et al., 2015; Prabakaran et al., 2018). LC-MS-based metabolomics approaches are widely used to profile complex biological extracts such as those from plants (Shimizu et al., 2018; Feussner and Feussner, 2019), being of particular importance for non-targeted plant metabolomics, mainly due to the plant kingdoms rich metabolite diversity (Gorrochategui et al., 2016; Wang et al., 2019). Compared to other analytical techniques, the main advantages of LC-MS are that it can cover a wide chemical diversity and a wide dynamic range; it is a complementary analytical technique to nuclear magnetic resonance (NMR) and gas chromatography-MS in metabolomics studies (Anderson et al., 2020; Yaglioglu et al., 2020). The traditional untargeted LC-MS device consists of an LC with a reverse-phase chromatography (RPC) column (with an inner diameter of 2.1 or $4.6 \mathrm{~mm}$ ) for analyses in front of a mass spectrometer. Although the separation range of RPC columns is quite wide, they cannot retain small polar metabolites well. Hydrophilic interaction liquid chromatographic (HILIC) columns are increasingly used for analyses of polar compounds (Wolf et al., 2012; Chai et al., 2018; Taraji et al., 2018), although they have a lower loading capacity than RPC columns, which results in wider peak shapes (Lurie et al., 2011).

The plant apoplast, which includes xylem sap, serves as an interface between the environment and the protoplast. It is not only a barrier against adverse stresses but also has multiple functions in metabolism and signal transduction (Zhang et al., 2008). Several studies have characterized plant defenses against biotic (Feussner and Feussner, 2019; Green et al., 2020) and abiotic (Hasanuzzaman et al., 2018; Chérel and Gaillard, 2019; $\mathrm{Lu}$ et al., 2019) stresses by analyzing the metabolites of the apoplast. The metabolites in xylem sap secreted from the root symplast not only reflect the physiological state of roots but also affect the growth and the development of above-ground plant parts (Zhang Z. et al., 2016). For cotton, K deficiency is a worldwide problem (Zhao et al., 2014). K deficiency leads to an imbalance of the phytohormone abscisic acid and cytokines in the xylem sap (Wang et al., 2012) and induces premature leaf senescence (Li et al., 2012; Hu et al., 2016). However, to the best of our knowledge, no previous study has investigated the response mechanism of cotton to $\mathrm{K}$ deficiency by analyzing the metabolic components of xylem sap.

\section{MATERIALS AND METHODS}

\section{Cultivar and Culturing Conditions}

Cotton cultivar "DP 99B" was used in this experiment. A randomized block design was employed, with eight plants per pot and 12 pots per treatment. Cotton seedlings were cultivated in a culture room of the Henan Institute of Science and Technology under a regime of 14-h light/10-h dark, with a temperature of $30 \pm 2^{\circ} \mathrm{C}$ during the day and at $25 \pm 2^{\circ} \mathrm{C}$ at night. 


\section{Culture of Seedlings}

Seeds of similar size were selected and sterilized with $9 \% \mathrm{H}_{2} \mathrm{O}_{2}$ for $30 \mathrm{~min}$. After having been rinsed with tap water, the seeds were planted in wet sand. As soon as the seedlings had reached the stage where two cotyledons were expanding from the seed case, they were transferred to containers with a nutrient solution with normal $\mathrm{K}(\mathrm{NK})$ concentration. After culturing for 3 days, the seedlings were again transferred to containers with normal or low $\mathrm{K}$ concentration to grow for a further 7 days; during this time, samples of xylem sap, roots, and leaves were collected.

The nutrient solution was continuously aerated and contained $2.5 \mathrm{mmol} \mathrm{L}^{-1} \mathrm{Ca}\left(\mathrm{NO}_{3}\right)_{2}, 1 \mathrm{mmol} \mathrm{L}{ }^{-1} \mathrm{MgSO}_{4}, 0.5 \mathrm{mmol} \mathrm{L}^{-1}$ $\mathrm{NH}_{4} \mathrm{H}_{2} \mathrm{PO}_{4}, 2 \times 10^{-4} \mathrm{mmol} \mathrm{L}^{-1} \mathrm{CuSO}_{4}, 1 \times 10^{-3} \mathrm{mmol} \mathrm{L}^{-1}$ $\mathrm{ZnSO}_{4}, 0.1 \mathrm{mmol} \mathrm{L}^{-1}$ EDTAFeNa, $2 \times 10^{-2} \mathrm{mmol} \mathrm{L}^{-1} \mathrm{H}_{3} \mathrm{BO}_{3}$, $5 \times 10^{-6} \mathrm{mmol} \mathrm{L}^{-1}\left(\mathrm{NH}_{4}\right)_{6} \mathrm{Mo}_{7} \mathrm{O}_{24}$, and $1 \times 10^{-3} \mathrm{mmol}$ $\mathrm{L}^{-1} \mathrm{MnSO}_{4}$. $\mathrm{K}$ was added in the form of $\mathrm{KCl}$, with a final concentration of $0.05 \mathrm{mmol} \mathrm{L}^{-1}$ in the LK culture solution and $2.5 \mathrm{mmol} \mathrm{L}^{-1}$ in the NK culture solution.

\section{Determining the Morphological Indexes of Cotton Seedlings}

An EPSON 12000XL scanner was utilized to scan the root, stem, and leaf, respectively, spread out on a transparent plastic tray after being separated from the cotton seedlings. Some water was usually added to the tray to benefit root spread. WinRHIZO Pro 2017 software was used to examine their stem length, total root length, root surface area, mean diameter of root, and root volume. The scanned seedling parts were weighed as fresh weight after water was allowed to drip for the roots to dry. Finally, fresh seedlings were placed in paper bags, baked at $105^{\circ} \mathrm{C}$ for $20 \mathrm{~min}$, and then dried at $80^{\circ} \mathrm{C}$ to a constant weight for weighing.

\section{Xylem Sap Collection and Preparation}

Xylem sap was collected via natural root pressure. In details, firstly, the up-ground part of a seedling was cut approximately $5 \mathrm{~cm}$ above the junction of the root and the stem; secondly, after washing the rootstock surface five times with distilled water to clean possible substances of pollution from phloem, the xylem sap was blotted with filter paper, then a latex tube was fitted over $0.5 \mathrm{~cm}$ rootstock, and the other end of the tube was put into a plastic centrifuge tube of $15 \mathrm{ml}$, which was placed in a foam box filled with ice. The sap of six to eight seedlings was collected into each plastic tube. The samples were frozen with liquid nitrogen and then kept at $-80^{\circ} \mathrm{C}$ for subsequent testing.

When exerting further experiments, the frozen collected sap was thawed and first coarsely filtered through a 0.25 $\mu \mathrm{m}$ inorganic filter membrane; the filtered xylem sap was transferred into a 3-KD ultra-centrifuge tube (Millipore's Amicon Ultra-4) to separate substances with molecular weight $>3 \mathrm{KD}$ and $<3 \mathrm{KD}$. The samples were centrifuged at $7,500 \mathrm{~g}$ for $45 \mathrm{~min}$ at $4^{\circ} \mathrm{C}$ to obtain a concentrated protein solution in the smaller and inner centrifuge tube and permeated metabolite and ion liquid in the bigger and outer centrifuge tube. The former was used to determine the free protein content and activity of peroxidase (POD) and superoxide dismutase (SOD) enzymes, and the latter was used to determine free sugar, amino acids, polyphenols, and the metabolite profile.

\section{Determination of Physiological Indicators of Xylem Sap}

\section{Determination of $\mathrm{pH}$ Value and Cation Contents}

The $\mathrm{pH}$ value was measured using a $\mathrm{pH}$ meter. The levels of $\mathrm{K}, \mathrm{Na}$ (sodium), Ca (calcium), Mg (magnesium), Fe (iron), and $\mathrm{Zn}$ (zinc) in the xylem sap was assessed via inductively coupled plasma luminescence spectrometry after diluting the sap with $2 \%$ $\mathrm{HCl}$, at a sap/ $\mathrm{HCl}$ ratio of 1:100, and then oscillating the samples at a speed of $100 \mathrm{~g}$ for $10 \mathrm{~min}$.

\section{Determination of Physiological Indexes Related to Stress Resistance}

The content of free protein was determined using the Coomassie brilliant blue method (Bradford, 1976), and the activities of POD and SOD enzymes were determined using the guaiacol (Zelinová et al., 2010) and NBT (Rukmini et al., 2004) methods, respectively. The contents of free sugars, amino acids, and polyphenols were measured using the anthrone (Li and Li, 2013), the ninhydrin (Sun et al., 2006), and the Folin phenol (Li et al., 2008) methods, respectively.

\section{Loading and Quality Control Sample Preparation}

The above-mentioned collected ultra-filtered sap in bigger and outer centrifuge tube $(200 \mu \mathrm{l})$ and pre-cooled methanol $(800 \mu \mathrm{l})$ were mixed and centrifuged for $30 \mathrm{~min}$ at $4^{\circ} \mathrm{C}$ at $13,000 \mathrm{~g}$; then, the supernatant was divided into four equal parts and lyophilized. The quality control (QC) samples were prepared by mixing aliquots of batch samples to create pooled samples according to the described methods (Sangster et al., 2006; Gika et al., 2007). Briefly, each filtered sap (20 $\mu \mathrm{l})$ was mixed with pre-cooled methanol of four times the volume and centrifuged for $30 \mathrm{~min}$ at $4^{\circ} \mathrm{C}$ at $13,000 \mathrm{~g}$, and then the supernatant was divided according to the same share allocation with single loading sample preparation and lyophilized. Each lyophilized sample was resolved with 20 $\mu \mathrm{l} 20 \%(\mathrm{v} / \mathrm{v})$ acetonitrile in water and analyzed via LC-MS using a Shimadzu LC20AD HPLC system coupled with a Triple TOF 5600 mass spectrometer (AB SCIEX). The order of sample loading was such that four QC samples were randomly assigned at the beginning and two QC samples were randomly allocated between every eight samples, being described in such a way that the QC samples should be randomly analyzed at the beginning and at the end (Sangster et al., 2006; Gika et al., 2007).

The prepared samples were kept at $4^{\circ} \mathrm{C}$ in the autosampler, and then $2 \mu \mathrm{l}$ aliquots were taken for analyses using a reversephase gradient LC device fitted with a Phenomenex Luna 3 $\mu \mathrm{m}$ C18 column $(150 \times 2.0 \mathrm{~mm})$ as well as analyses using a hydrophilic interaction chromatography gradient LC fitted with a TSK gel Amide-80 $3 \mu \mathrm{m}$ column $(150 \times 2.0 \mathrm{~mm})$. 


\section{Reversed-Phase Chromatography Separation}

For RPC, we used a binary solvent system delivered as a gradient of $0.1 \%(\mathrm{v} / \mathrm{v})$ formic acid in water (solvent $\mathrm{A})$ and $0.1 \%(\mathrm{v} / \mathrm{v})$ formic acid in pure acetonitrile (solvent B) using a flow rate of $300 \mu \mathrm{l} \mathrm{min}{ }^{-1}$, with the column maintained at $45^{\circ} \mathrm{C}$. The chromatographic column was equilibrated with $98 \%$ solvent A. The starting gradient conditions were $98 \%$ solvent $\mathrm{A}$ and $2 \%$ solvent B. Then, a linear gradient was conducted up to $65 \%$ solvent B over $20 \mathrm{~min}$, at which point the solvent composition was increased to $100 \%$ solvent B for $5 \mathrm{~min}$. Then, the column was returned to $2 \%$ solvent $B$ over the next $1 \mathrm{~min}$ and maintained at this level for $4 \mathrm{~min}$, for a total cycle time of $30 \mathrm{~min} / \mathrm{sample}$.

\section{Hydrophilic Interaction Chromatography Separation}

For HILIC, we used a binary solvent system delivered as a gradient of $0.1 \%(\mathrm{v} / \mathrm{v})$ formic acid and $10 \mathrm{mM}$ ammonium formate in water (solvent $\mathrm{A}$ ) and $0.1 \%(\mathrm{v} / \mathrm{v})$ formic acid in pure acetonitrile (solvent B) using a flow rate of $200 \mu \mathrm{l} \mathrm{min}{ }^{-1}$, with the column maintained at $45^{\circ} \mathrm{C}$. The chromatographic column was equilibrated with $95 \%$ solvent $\mathrm{B}$. The starting gradient conditions were $5 \%$ solvent $\mathrm{A}$ and $95 \%$ solvent $\mathrm{B}$. Then, a linear gradient was conducted down to $70 \%$ solvent B over $24 \mathrm{~min}$, after which the composition was further decreased to $10 \%$ solvent $\mathrm{B}$ for $4 \mathrm{~min}$ and maintained at this level for $2 \mathrm{~min}$. Then, the solvent composition was again returned to $95 \%$ over $1 \mathrm{~min}$ and maintained at this level for $4 \mathrm{~min}$, for a total cycle time of $35 \mathrm{~min} /$ sample.

\section{Mass Spectrometer Identification}

The compounds separated by LC were analyzed in both positiveand negative-ion modes. The mass spectrometer was operated in the positive and the negative ESI modes with a Duo Spray TM source (AB SCIEX, Canada) connected to an MS/MS (Triple TOF 5600, AB SCIEX). The following parameter settings were used: ion spray voltage, $\pm 5,500 \mathrm{~V}$; ion source temperature, $600^{\circ} \mathrm{C}$; curtain gas, $30 \mathrm{psi}$; both ion source gas 1 and gas 2 , $55 \mathrm{psi}$; TOF-MS scan, m/z 100-1,000 Da of mass range; and scan accumulation time, $0.25 \mathrm{~s} /$ spectra. In high sensitivity mode, they were as follows: ion scan $\mathrm{m} / \mathrm{z}$ range, 50-1,000 Da; ion scan accumulation time, $0.07 \mathrm{~s} / \mathrm{spectra}$; declustering potential, $\pm 60 \mathrm{~V}$; and collision energy, $\pm 20 \mathrm{~V}$. In addition, information-dependent acquisition (IDA) was used to acquire MS/MS spectra for ions matching the IDA criteria (excluding isotopes within $4 \mathrm{Da}$, candidate ions to monitor per cycle: 10 ).

\section{Metabolomic Data Processing}

MS data (wiff.scan files) were converted into MzXML files using ProteoWizard MSConvert and processed by XCMS for feature detection, retention time correction, and alignment. The metabolites were identified by mass (the errors were less than $25 \mathrm{ppm}$ ) and according to MS/MS data that were queried and matched with a laboratory standards database developed by Shanghai Applied Protein Technology Co., Ltd.
In extracted ion features, only variables with more than $50 \%$ of the non-zero measurement values in at least one group were retained. Progenesis QI (Non-linear Dynamics) was used for data processing, statistical analyses, and the selection and the identification of significantly different compounds. Specifically, from the resulting chromatograms, mass spectra peaks (compound ions) were aligned (score $>80$ as better alignment), picked [relative standard deviation (RSD) among all QC sample runs < 30\%] with an $\mathrm{m} / \mathrm{z}$ and a retention time, and normalized. Among the picked and normalized peaks, significantly different compounds between the LK and the NK groups were screened and selected by partial least squares discriminant analysis (PLS-DA) [variable importance for the projection (VIP) score $>1.0$ ] and volcano plot $[p<0.05$; fold change $(\mathrm{FC})>2$ or $<0.5]$. Then, the selected compounds were tentatively identified using MetaScope based on neutral mass $(\mathrm{m} / \mathrm{z}$ tolerance $10 \mathrm{ppm}$ ), retention time (for no fragments matching), and fragments (fragment score $>60$ ). Hierarchical clustering analyses were used to evaluate the reasonability of the significantly different compounds between the groups.

Variables (metabolites) that significantly contributed to the clustering and discrimination were identified according to a threshold of VIP values (VIP > 1), which could be generated after PLS-DA processing. To select potential biomarkers worthy of preferential study in the next step, these different metabolites were validated using a $t$-test.

\section{Statistical Analyses}

Three biological replicates were established to quantify cotton seedling growth; the levels of minerals, free sugars, free proteins, malondialdehyde (MDA), polyphenols, and amino acids in sap; the activities of G-POD and SOD in sap; and sap $\mathrm{pH}$. Eight biological replicates were used for quantitative analyses of metabolites in xylem sap for each treatment. Student's test was used to compare the differences between the LK and the NK treatments.

\section{RESULTS}

\section{Changes in Seedling Growth, Mineral Contents, and Physiological Traits of Cotton Under K Deficiency}

The cotton cultivar DP 99B showed obvious thin plants after 7 days of LK stress (Table 1). Compared to control, some morphological characters of 3-day-old cotton seedlings treated with LK for 7 days were statistically significantly different, including lower dry weights of leaves, stems, and roots and shorter stems and total roots (Table 1). In addition, because there were no significant differences in mean root diameter between the treatments, the differences in root length resulted in significant differences in root surface area and root volume.

Compared to controls, the LK group had lower $\mathrm{pH}$, levels of five mineral nutrients ( $\mathrm{K}, \mathrm{Na}, \mathrm{Mg}, \mathrm{Fe}$, and $\mathrm{Zn}$ ), free sugars, free proteins, and polyphenols, and activities of G-POD and SOD but 
had significantly higher xylem sap volume and $\mathrm{Ca}^{2+}, \mathrm{MDA}$, and amino acid levels (Tables 2, 3).

\section{Analyses of Reproducibility of HPLC-MS/MS}

Metabolites of 16 samples (eight different biological samples from each treatment) and six QC samples were analyzed by HPLCMS/MS. The HILIC-positive, HILIC-negative, RPC-positive, and RPC-negative total ion current chromatograms obtained from these analyses are shown in Figure 1. The retention peaks of HILIC and RPC mode were detected at around 30.5 and $25.8 \mathrm{~min}$, respectively; therefore, the retention time was set to 35 and 30 min for HILIC and RPC mode analyses, respectively.

The reproducibility of both peak intensity and retention time in each mode is very important when attempting to explain the differences among samples. As shown in Figure 1, the retention time and the peak intensity of all samples in each mode were similar, indicating a high degree of reproducibility of our mass spectrometry data.

\section{Metabolite Profiles}

There were $8,188,4,820,2,442$, and 5,972 detected peaks in the HILIC-positive, HILIC-negative, RPC-positive, and RPCnegative modes, respectively (Table 4). The numbers of compounds in samples with peak strength RSD $\leq 30 \%$ were 642 , 186,329 , and 565 in these four modes, respectively.

After the data were cleaned and normalized, a principal component analysis (PCA) of all samples was used to assess the experimental quality. Taking the HILIC-positive ion mode as an example, the PCA score plot (Figure 2A) pooled the QC samples together, indicating that the HPLC-MS/MS process met the required qualifications. However, it was difficult to discriminate between the two treatments in the unsupervised multivariate analyses (Figure 2A). Thus, supervised multivariate analyses using PLS-DA were conducted, which clustered the eight biological replicates of each treatment group, verifying the experimental design and robustness of the method. Two plots of PCA and PLS-DA score were drawn with the top two principal components. The largest variation was represented by principal component 1 , which accounted for $31.7 \%$ of the PCA score plot (Figure 2A) and 34.8\% of the PLS-DA score plot (Figure 2B). The PLS-DA model clearly distinguished the two treatments based on the LC-MS/MS data.

The VIP score reflects the importance of the variables in the PLS-DA model and was applied to measure the influence of the expression intensity of metabolites on the classification and the interpretation ability of samples of each group, thus helping to screen important metabolites (usually VIP score $>1.0$ as screening criteria). Based on the PLS-DA analyses, the critical

TABLE 1 | Changes in seedling growth of cotton under $K$ deficiency.

\begin{tabular}{|c|c|c|c|c|c|c|c|c|}
\hline \multirow[t]{2}{*}{ Class } & Leaf $^{a}$ & Stem $^{a}$ & Root $^{a}$ & Stem length ${ }^{a}$ & Total root length ${ }^{a}$ & \multirow{2}{*}{$\frac{\text { Mean root diameter }}{\mathrm{mm} \mathrm{plant}^{-1}}$} & \multirow{2}{*}{$\frac{\text { Root surface area }}{\mathrm{cm}^{2} \text { plant }^{-1}}$} & \multirow{2}{*}{$\frac{\text { Root volume }}{\text { cm }^{3} \text { plant }^{-1}}$} \\
\hline & \multicolumn{3}{|c|}{ g dry weight plant ${ }^{-1}$} & \multicolumn{2}{|c|}{ cm plant ${ }^{-1}$} & & & \\
\hline LK & $0.13 \pm 0.010$ & $0.05 \pm 0.006$ & $0.04 \pm 0.003$ & $18.96 \pm 4.03$ & $511.21 \pm 54.36$ & $0.38 \pm 0.01$ & $62.73 \pm 8.29$ & $0.62 \pm 0.11$ \\
\hline NK & $0.20 \pm 0.002$ & $0.08 \pm 0.002$ & $0.06 \pm 0.001$ & $22.96 \pm 0.79$ & $782.81 \pm 28.95$ & $0.39 \pm 0.03$ & $93.34 \pm 0.41$ & $0.89 \pm 0.03$ \\
\hline
\end{tabular}

LK, low K; NK, normal K.

a There was a significant difference between $L K$ and NK treatments according to t-test, $p<0.05, r=3$.

TABLE 2 | Changes in $\mathrm{pH}$ and mineral nutrient contents of cotton xylem sap under $\mathrm{K}$ deficiency.

\begin{tabular}{|c|c|c|c|c|c|c|c|c|}
\hline \multirow[t]{2}{*}{ Class } & \multirow[t]{2}{*}{$\mathrm{pH}^{\mathrm{a}}$} & \multirow{2}{*}{$\begin{array}{c}\text { Xylem sap volume }^{\mathrm{a}} \\
\text { ml plant }^{-1}\end{array}$} & $\mathbf{K}^{\mathbf{a}}$ & $\mathrm{Na}^{\mathrm{a}}$ & $\mathrm{Ca}^{\mathrm{a}}$ & $\mathbf{M g}^{\mathrm{a}}$ & $\mathrm{Fe}^{\mathrm{a}}$ & $Z^{a}$ \\
\hline & & & \multicolumn{6}{|c|}{$\mathrm{mg} \mathrm{L}^{-1}$ xylem sap } \\
\hline LK & $5.41 \pm 0.06$ & $229.53 \pm 31.65$ & $157.39 \pm 9.67$ & $184.46 \pm 15.98$ & $988.00 \pm 51.28$ & $412.49 \pm 14.83$ & $7.61 \pm 1.34$ & $6.44 \pm 1.48$ \\
\hline NK & $5.97 \pm 0.09$ & $181.53 \pm 37.09$ & $240.49 \pm 43.47$ & $224.96 \pm 22.30$ & $830.15 \pm 80.74$ & $457.25 \pm 31.73$ & $14.08 \pm 4.56$ & $13.09 \pm 3.76$ \\
\hline
\end{tabular}

LK, low K; NK, normal K.

a There was a significant difference between $L K$ and NK treatments according to t-test, $p<0.05, r=3$.

TABLE 3 | Changes in the physiological characteristics of cotton xylem sap under K deficiency.

\begin{tabular}{|c|c|c|c|c|c|c|c|}
\hline \multirow[t]{2}{*}{ Class } & \multirow{2}{*}{$\begin{array}{c}\text { MDA }^{\mathrm{a}} \\
\mathrm{nmol} \mathrm{ml^{-1 }}\end{array}$} & G-POD activity ${ }^{a}$ & SOD activity ${ }^{a}$ & Free sugar ${ }^{a}$ & Free protein ${ }^{a}$ & Polyphenol $^{a}$ & Amino acid $^{a}$ \\
\hline & & \multicolumn{2}{|c|}{$\mathrm{U} \mathrm{ml}^{-1}$ xylem sap } & \multicolumn{4}{|c|}{$\mu \mathrm{g} \mathrm{ml}^{-1}$} \\
\hline LK & $48.24 \pm 11.20$ & $54.00 \pm 11.63$ & $4.79 \pm 0.57$ & $12.25 \pm 1.65$ & $2.06 \pm 0.13$ & $37.71 \pm 1.27$ & $72.06 \pm 5.20$ \\
\hline NK & $43.51 \pm 19.68$ & $82.15 \pm 13.84$ & $5.60 \pm 0.19$ & $16.16 \pm 3.78$ & $3.03 \pm 0.41$ & $41.93 \pm 1.83$ & $53.05 \pm 8.02$ \\
\hline
\end{tabular}

LK, low K; NK, normal K.

a There was a significant difference between $L K$ and NK treatments according to t-test, $p<0.05, r=3$. 


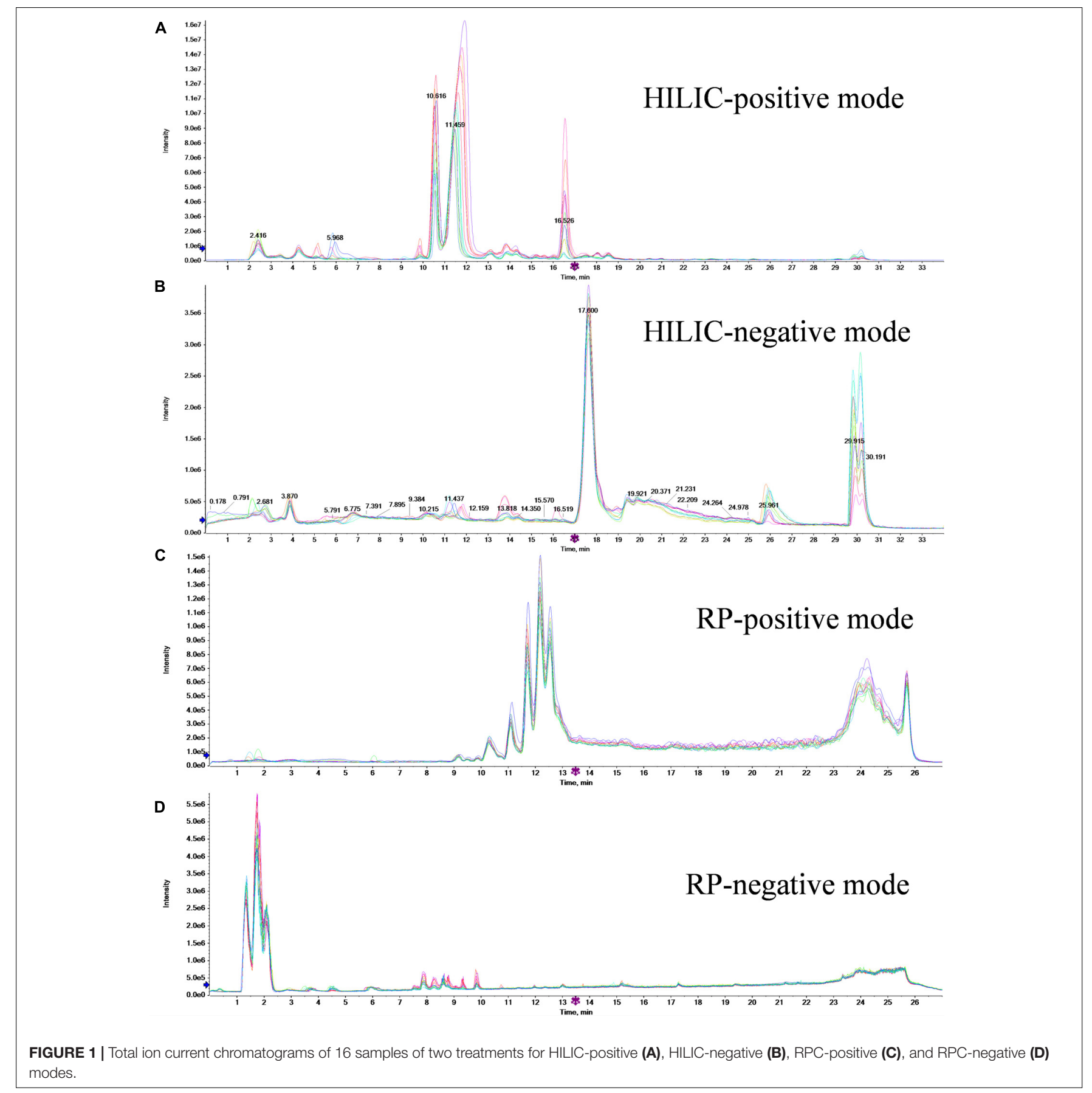

TABLE 4 | Significantly different compounds screened and selected by combining partial least squares discriminant analysis and volcano plot under different separation and analysis modes.

\begin{tabular}{|c|c|c|c|c|}
\hline Items & \multicolumn{2}{|c|}{ Hydrophilic interaction liquid chromatographic separation } & \multicolumn{2}{|c|}{ Reverse-phase chromatography separation } \\
\hline Peaks(relative standard deviation < 30\%) & 642 & 186 & 329 & 565 \\
\hline Significantly different compounds & 56 & 3 & 0 & 23 \\
\hline
\end{tabular}



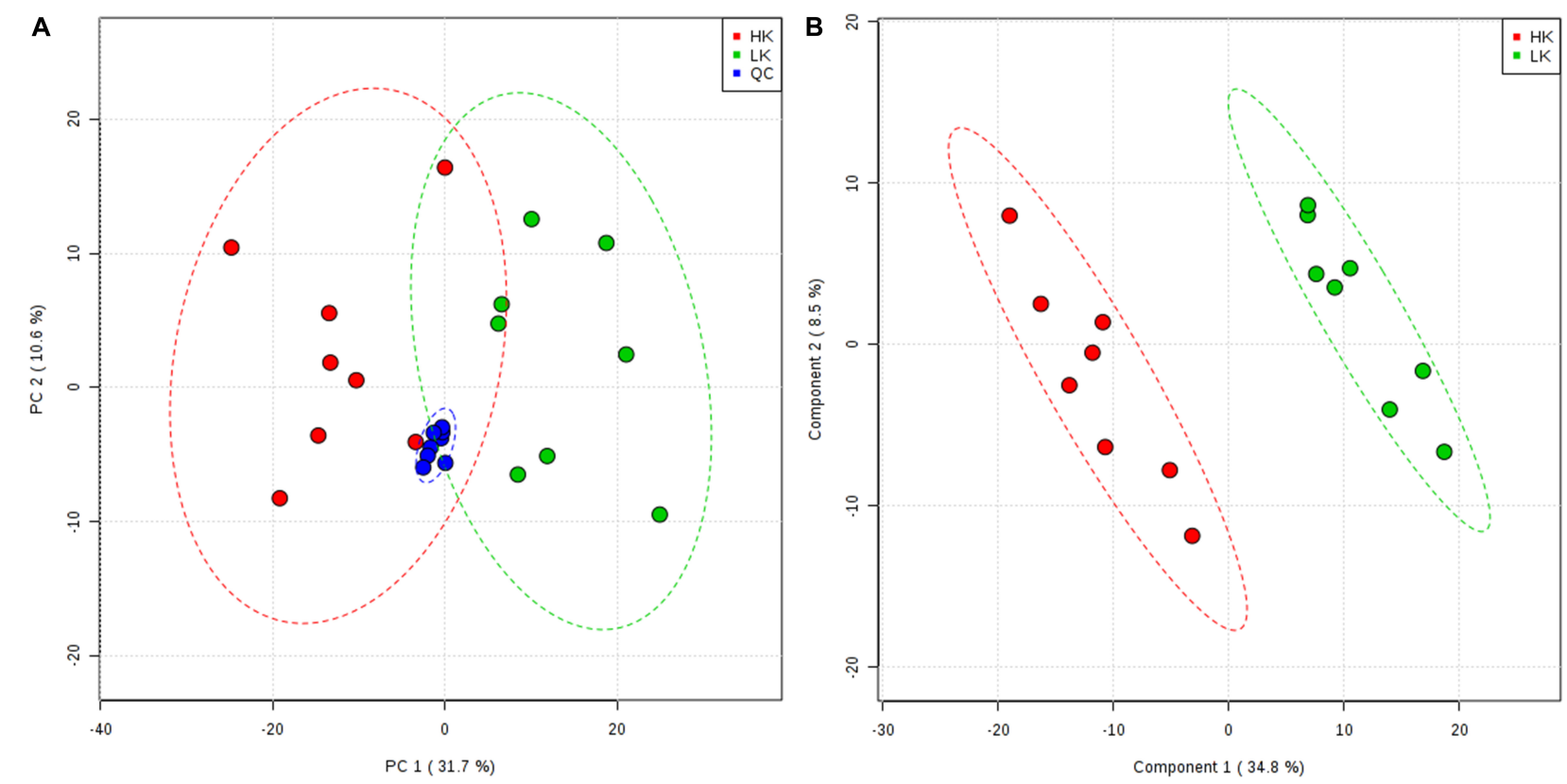

FIGURE 2 | Principal component analysis score plot (A) and partial least squares discriminant analysis score plot (B) from the HILIC-POS mode.
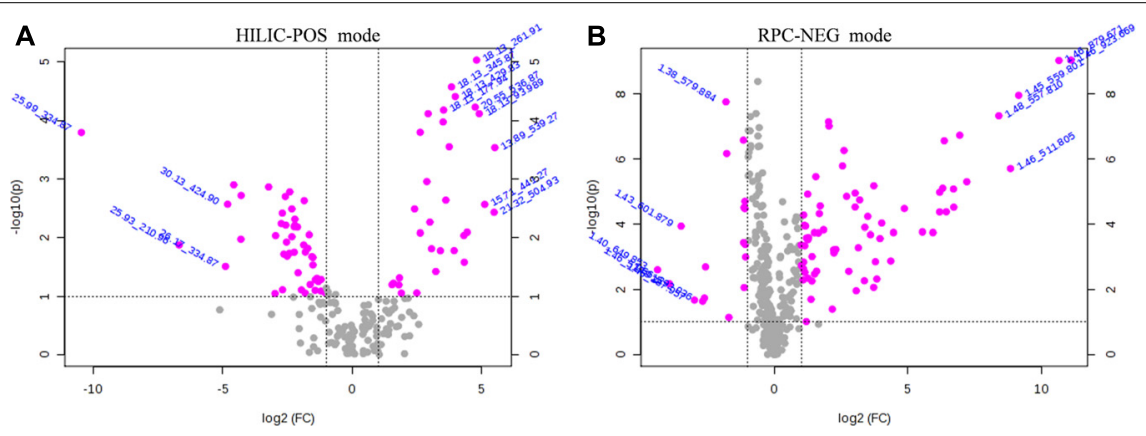

FIGURE 3 | Volcano plots of HILIC-POS (A) and RPC-NEG (B) showing metabolomic data. The pink dots indicate points-of-interest that display both large-magnitude fold changes (x-axis) and high statistical significance $\left[-\log _{10}(p), y\right.$-axis]. The dashed line shows where $p=0.05$, with points above the line at $p<0.05$ and points below the line at $p>0.05$. Points at a fold change less than $2\left(\log _{2} 2=1\right)$ and $p>0.05\left(-\log _{10} 0.05=1.3\right)$ are shown in gray.

$p$-value was set to 0.05 for significantly different variables with FC $>2.0$. Following the criteria above, 82 significantly different endogenous metabolites (56 in HILIC-POS mode, three in HILIC-NEG, 23 in RPC-NEG mode, and 0 in RPC-POS) between the NK and the LK treatments were screened by volcano plots (Figure 3) for further study.

\section{Cluster Analyses of Altered Metabolites Under LK Stress}

Three heatmaps were generated as graphical representations of the up- and down-regulated expressions of metabolites. Among the 82 metabolites, 38 in the LK treatment showed 2-fold higher upregulation (red color) vs. controls, while 44 showed less than 0.5 -fold downregulation (blue color).

More specifically, 34, two, and two metabolites were up-regulated in the HILIC-POS (Figure 4A), HILIC-NEG
(Figure 4B), and RPC-NEG (Figure 4C) modes, respectively, with glycerophosphocholine showing the highest increase in upregulation $(\mathrm{FC}=29.00)$ (Table 5). Because heatmaps showed stable repeatability among different samples in the same treatment, 22, one, and 22 down-regulated metabolites could also be easily found in the blue area, i.e., in HILIC-POS (Figure 4A), HILIC-NEG (Figure 4B), and RPC-NEG (Figure 4C) modes, respectively. For example, 6 -hydroxydaidzein $4^{\prime}$-glucoside with $\mathrm{FC}=0.02$ was in the end among the down-regulated metabolites (Table 5).

\section{Changes in Primary and Secondary Metabolites Between the Two \\ Treatments}

According to the traditional classification method and referring to the classifications of Kyoto Encyclopedia of Genes and 


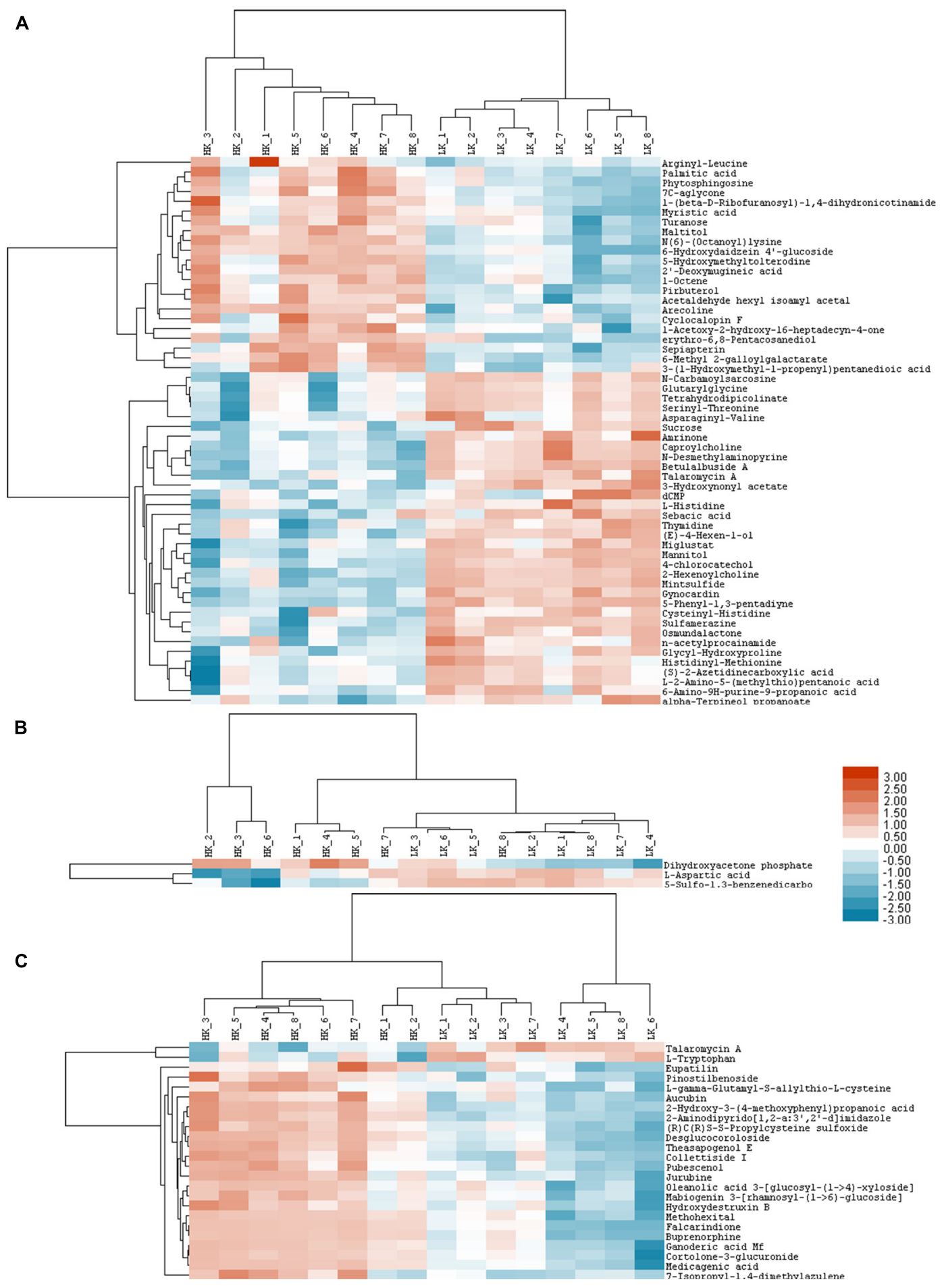

FIGURE 4 | Heat maps of HILIC-POS (A), HILIC-NEG (B), and RPC-NEG (C) modes.

Genomes (KEGG) database and Irchhaiya et al. (2015), 82 different metabolites were classified into 43 primary metabolites and 39 secondary metabolites. These primary metabolites were further divided into $19 \alpha$-amino acids (including derivatives), six carbohydrates (including derivatives), 14 lipids (including derivatives), and four nucleotides (including derivatives). The secondary metabolites included 14 terpenoids, 11 phenols, six alkaloids, and 8 "others" (Figure 5).

Compared to controls, the sub-class ratios of 25 up-regulated and 18 down-regulated primary metabolites in the LK treatment 
TABLE 5 | Comparison of metabolites in the xylem sap of cotton seedlings between low $\mathrm{K}(\mathrm{LK})$ and normal $\mathrm{K}(\mathrm{NK})$ treatments.

\begin{tabular}{|c|c|c|c|c|c|c|c|c|c|}
\hline Metabolites & Class & Subclass & FC (LK/NK) & Mode & Compound ID & Adducts & Formula & $P$-value & $\begin{array}{l}\text { Variable importance for } \\
\text { the projection score }\end{array}$ \\
\hline Glycerophosphocholine & PM & Lipid & 29.00 & HILIC-POS & 28.17_258.1093m/z & $\mathrm{M}+\mathrm{H}$ & $\mathrm{C}_{8} \mathrm{H}_{20} \mathrm{NO}_{6} \mathrm{P}$ & 0.0070 & 1.2025 \\
\hline Tetrahydrodipicolinate & PM & $\alpha$-Amino acid & 16.72 & HILIC-POS & 23.38_189.0863m/z & $\mathrm{M}+\mathrm{NH}_{4}$ & $\mathrm{C}_{7} \mathrm{H}_{9} \mathrm{NO}_{4}$ & 0.0087 & 1.1777 \\
\hline Gynocardin & SM & Other & 14.72 & HILIC-POS & 22.44_304.1004m/z & $\mathrm{M}+\mathrm{H}$ & $\mathrm{C}_{12} \mathrm{H}_{17} \mathrm{NO}_{8}$ & 0.0000 & 1.6790 \\
\hline Betulalbuside A & PM & Lipid & 13.77 & HILIC-POS & 3.76_333.1917m/z & $\mathrm{M}+\mathrm{H}$ & $\mathrm{C}_{16} \mathrm{H}_{28} \mathrm{O}_{7}$ & 0.0000 & 1.6347 \\
\hline Glutarylglycine & PM & $\alpha$-Amino acid & 12.43 & HILIC-POS & 23.41_207.0969m/z & $\mathrm{M}+\mathrm{NH}_{4}$ & $\mathrm{C}_{7} \mathrm{H}_{11} \mathrm{NO}_{5}$ & 0.0213 & 1.0624 \\
\hline Mintsulfide & SM & Terpenoid & 12.29 & HILIC-POS & 3.09_237.1694m/z & $\mathrm{M}+\mathrm{H}$ & $\mathrm{C}_{15} \mathrm{H}_{24} \mathrm{~S}$ & 0.0000 & 1.6686 \\
\hline 2-Hexenoylcholine & PM & Lipid & 8.68 & HILIC-POS & 3.40_223.1540m/z & $\mathrm{M}+\mathrm{Na}$ & $\mathrm{C}_{11} \mathrm{H}_{22} \mathrm{NO}_{2}$ & 0.0000 & 1.6083 \\
\hline Methyl 4-chloro-1H-indole-3-acetate & SM & Alkaloid & 7.47 & HILIC-POS & 9.59_265.0738m/z & $\mathrm{M}+\mathrm{ACN}+\mathrm{H}$ & $\mathrm{C}_{11} \mathrm{H}_{10} \mathrm{ClNO}_{2}$ & 0.0001 & 1.5174 \\
\hline (E)-4-Hexen-1-ol & PM & Lipid & 6.14 & HILIC-POS & $16.28 \_118.1227 \mathrm{~m} / \mathrm{z}$ & $\mathrm{M}+\mathrm{NH}_{4}$ & $\mathrm{C}_{6} \mathrm{H}_{12} \mathrm{O}$ & 0.0002 & 1.5019 \\
\hline Serinyl-threonine & PM & $\alpha$-Amino acid & 5.97 & HILIC-POS & 23.33_229.0788m/z & $\mathrm{M}+\mathrm{Na}$ & $\mathrm{C}_{7} \mathrm{H}_{14} \mathrm{~N}_{2} \mathrm{O}_{5}$ & 0.0038 & 1.2671 \\
\hline N-Carbamoylsarcosine & PM & $\alpha$-Amino acid & 5.39 & HILIC-POS & 25.29_132.0529n & $\mathrm{M}+\mathrm{H}, \mathrm{M}+\mathrm{Na}$ & $\mathrm{C}_{4} \mathrm{H}_{8} \mathrm{~N}_{2} \mathrm{O}_{3}$ & 0.0026 & 1.3025 \\
\hline 5-Phenyl-1,3-pentadiyne & SM & Other & 5.36 & HILIC-POS & 4.78_158.0963m/z & $\mathrm{M}+\mathrm{NH}_{4}$ & $\mathrm{C}_{11} \mathrm{H}_{8}$ & 0.0000 & 1.7931 \\
\hline N-Desmethylaminopyrine & SM & Alkaloid & 5.20 & HILIC-POS & 3.45_259.1539m/z & $\mathrm{M}+\mathrm{ACN}+\mathrm{H}$ & $\mathrm{C}_{12} \mathrm{H}_{15} \mathrm{~N}_{3} \mathrm{O}$ & 0.0000 & 1.5733 \\
\hline Histidinyl-methionine & PM & $\alpha$-Amino acid & 4.41 & HILIC-POS & 29.54_328.1425m/z & $\mathrm{M}+\mathrm{ACN}+\mathrm{H}$ & $\mathrm{C}_{11} \mathrm{H}_{18} \mathrm{~N}_{4} \mathrm{O}_{3} \mathrm{~S}$ & 0.0084 & 1.1826 \\
\hline Caproylcholine & PM & Lipid & 4.11 & HILIC-POS & 3.44_241.1434m/z & $M+K$ & $\mathrm{C}_{11} \mathrm{H}_{24} \mathrm{NO}_{2}$ & 0.0001 & 1.5411 \\
\hline L-Aspartic acid & PM & $\alpha$-Amino acid & 4.04 & HILIC-NEG & $25.22 \_114.0192 \mathrm{~m} / \mathrm{z}$ & $\mathrm{M}-\mathrm{H}_{2} \mathrm{O}-\mathrm{H}$ & $\mathrm{C}_{4} \mathrm{H}_{7} \mathrm{NO}_{4}$ & 0.0260 & 1.8390 \\
\hline Osmundalactone & SM & Phenol & 3.95 & HILIC-POS & $9.26 \_129.0543 \mathrm{~m} / \mathrm{z}$ & $\mathrm{M}+\mathrm{H}$ & $\mathrm{C}_{6} \mathrm{H}_{8} \mathrm{O}_{3}$ & 0.0002 & 1.4901 \\
\hline L-Histidine & PM & $\alpha$-Amino acid & 3.77 & HILIC-POS & 29.05_156.0764m/z & $M+H$ & $\mathrm{C}_{6} \mathrm{H}_{9} \mathrm{~N}_{3} \mathrm{O}_{2}$ & 0.0046 & 1.2474 \\
\hline 6-Amino-9H-purine-9-propanoic acid & PM & Nucleotide & 3.43 & HILIC-POS & 24.32_230.0628m/z & $\mathrm{M}+\mathrm{Na}$ & $\mathrm{C}_{8} \mathrm{H}_{9} \mathrm{~N}_{5} \mathrm{O}_{2}$ & 0.0089 & 1.1749 \\
\hline 4-Chlorocatechol & SM & Phenol & 2.98 & HILIC-POS & 29.88_182.9617m/z & $M+K$ & $\mathrm{C}_{6} \mathrm{H}_{5} \mathrm{ClO}_{2}$ & 0.0000 & 1.5644 \\
\hline Glycyl-hydroxyproline & PM & $\alpha$-Amino acid & 2.90 & HILIC-POS & 25.71_230.1130m/z & $\mathrm{M}+\mathrm{ACN}+\mathrm{H}$ & $\mathrm{C}_{7} \mathrm{H}_{12} \mathrm{~N}_{2} \mathrm{O}_{4}$ & 0.0056 & 1.2269 \\
\hline dCMP & PM & Nucleotide & 2.78 & HILIC-POS & 19.35_325.0894m/z & $\mathrm{M}+\mathrm{NH}_{4}$ & $\mathrm{C}_{9} \mathrm{H}_{14} \mathrm{~N}_{3} \mathrm{O}_{7} \mathrm{P}$ & 0.0277 & 1.0240 \\
\hline Asparaginyl-valine & PM & $\alpha$-Amino acid & 2.75 & HILIC-POS & 29.14_249.1559m/z & $\mathrm{M}+\mathrm{NH}_{4}$ & $\mathrm{C}_{9} \mathrm{H}_{17} \mathrm{~N}_{3} \mathrm{O}_{4}$ & 0.0269 & 1.0283 \\
\hline n-Acetylprocainamide & SM & Phenol & 2.63 & HILIC-POS & 3.02_295.2124m/z & $\mathrm{M}+\mathrm{NH}_{4}$ & $\mathrm{C}_{15} \mathrm{H}_{23} \mathrm{~N}_{3} \mathrm{O}_{2}$ & 0.0067 & 1.2082 \\
\hline 5-Sulfo-1,3-benzenedicarboxylic acid & SM & Phenol & 2.61 & HILIC-NEG & 29.86_245.9819n & $\mathrm{M}-\mathrm{H}_{2} \mathrm{O}-\mathrm{H}, \mathrm{M}-\mathrm{H}$ & $\mathrm{C}_{8} \mathrm{H}_{6} \mathrm{O}_{7} \mathrm{~S}$ & 0.0040 & 2.2210 \\
\hline Propyl propane thiosulfonate & SM & Other & 2.55 & HILIC-POS & 3.76_229.1072m/z & $\mathrm{M}+\mathrm{H}$ & $\mathrm{C}_{11} \mathrm{H}_{16} \mathrm{O}_{5}$ & 0.0002 & 1.4824 \\
\hline Talaromycin A & SM & Other & 2.51 & HILIC-POS & 3.68_272.1859m/z & $\mathrm{M}+\mathrm{ACN}+\mathrm{H}$ & $\mathrm{C}_{12} \mathrm{H}_{22} \mathrm{O}_{4}$ & 0.0004 & 1.4473 \\
\hline Cysteinyl-histidine & PM & $\alpha$-Amino acid & 2.49 & HILIC-POS & 5.02_281.0676m/z & $\mathrm{M}+\mathrm{Na}$ & $\mathrm{C}_{9} \mathrm{H}_{14} \mathrm{~N}_{4} \mathrm{O}_{3} \mathrm{~S}$ & 0.0096 & 1.1662 \\
\hline Sucrose & PM & Carbohydrate & 2.43 & HILIC-POS & 25.41_365.1061m/z & $\mathrm{M}+\mathrm{Na}$ & $\mathrm{C}_{12} \mathrm{H}_{22} \mathrm{O}_{11}$ & 0.0023 & 1.3152 \\
\hline
\end{tabular}


TABLE 5 | Continued

\begin{tabular}{|c|c|c|c|c|c|c|c|c|c|}
\hline Metabolites & Class & Subclass & FC (LK/NK) & Mode & Compound ID & Adducts & Formula & $P$-value & $\begin{array}{l}\text { Variable importance for } \\
\text { the projection score }\end{array}$ \\
\hline (S)-2-Azetidinecarboxylic acid & PM & $\alpha$-Amino acid & 2.37 & HILIC-POS & 29.22_102.0551m/z & $\mathrm{M}+\mathrm{H}$ & $\mathrm{C}_{4} \mathrm{H}_{7} \mathrm{NO}_{2}$ & 0.0087 & 1.1786 \\
\hline L-2-Amino-5-(methylthio)pentanoic acid & PM & $\alpha$-Amino acid & 2.37 & HILIC-POS & 29.22_164.0732m/z & $\mathrm{M}+\mathrm{H}$ & $\mathrm{C}_{6} \mathrm{H}_{13} \mathrm{NO}_{2} \mathrm{~S}$ & 0.0113 & 1.1470 \\
\hline Talaromycin A & SM & Other & 2.23 & RPC-NEG & 12.33_275.1491m/z & $\mathrm{M}+\mathrm{FA}-\mathrm{H}$ & $\mathrm{C}_{12} \mathrm{H}_{22} \mathrm{O}_{4}$ & 0.0000 & 1.3110 \\
\hline Thymidine & PM & Nucleotide & 2.22 & HILIC-POS & 16.27_281.0513m/z & $M+K$ & $\mathrm{C}_{10} \mathrm{H}_{14} \mathrm{~N}_{2} \mathrm{O}_{5}$ & 0.0056 & 1.2268 \\
\hline Mannitol & PM & Carbohydrate & 2.20 & HILIC-POS & 19.64_205.0679m/z & $\mathrm{M}+\mathrm{Na}$ & $\mathrm{C}_{6} \mathrm{H}_{14} \mathrm{O}_{6}$ & 0.0000 & 1.6456 \\
\hline L-Tryptophan & PM & $\alpha$-Amino acid & 2.20 & RPC-NEG & 5.87_203.0820m/z & $\mathrm{M}-\mathrm{H}$ & $\mathrm{C}_{11} \mathrm{H}_{12} \mathrm{~N}_{2} \mathrm{O}_{2}$ & 0.0090 & 1.0610 \\
\hline alpha-Terpineol propanoate & SM & Terpenoid & 2.16 & HILIC-POS & 16.27_228.1957m/z & $\mathrm{M}+\mathrm{NH}_{4}$ & $\mathrm{C}_{13} \mathrm{H}_{22} \mathrm{O}_{2}$ & 0.0023 & 1.3141 \\
\hline Sebacic acid & PM & Lipid & 2.04 & HILIC-POS & 4.13_244.1545m/z & $\mathrm{M}+\mathrm{ACN}+\mathrm{H}$ & $\mathrm{C}_{10} \mathrm{H}_{18} \mathrm{O}_{4}$ & 0.0014 & 1.3593 \\
\hline 3-Hydroxynonyl acetate & PM & Lipid & 2.04 & HILIC-POS & 8.92_244.1915m/z & $\mathrm{M}+\mathrm{ACN}+\mathrm{H}$ & $\mathrm{C}_{11} \mathrm{H}_{22} \mathrm{O}_{3}$ & 0.0002 & 1.4997 \\
\hline Aucubin & SM & Terpenoid & 0.50 & RPC-NEG & 7.15_383.0721m/z & $M+K-2 H$ & $\mathrm{C}_{15} \mathrm{H}_{22} \mathrm{O}_{9}$ & 0.0000 & 1.3010 \\
\hline 1-(beta-D-Ribofuranosyl)-1,4-dihydronicotinamide & SM & Alkaloid & 0.48 & HILIC-POS & 30.04_279.0942m/z & $\mathrm{M}+\mathrm{Na}$ & $\mathrm{C}_{11} \mathrm{H}_{16} \mathrm{~N}_{2} \mathrm{O}_{5}$ & 0.0010 & 1.3842 \\
\hline Turanose & PM & Carbohydrate & 0.48 & HILIC-POS & 22.50_360.1512m/z & $\mathrm{M}+\mathrm{NH}_{4}$ & $\mathrm{C}_{12} \mathrm{H}_{22} \mathrm{O}_{11}$ & 0.0188 & 1.0796 \\
\hline 7-Isopropyl-1,4-dimethylazulene & SM & Terpenoid & 0.48 & RPC-NEG & 8.66_441.2811m/z & $2 \mathrm{M}+\mathrm{FA}-\mathrm{H}$ & $\mathrm{C}_{15} \mathrm{H}_{18}$ & 0.0050 & 1.1140 \\
\hline Acetaldehyde hexyl isoamyl acetal & PM & Lipid & 0.47 & HILIC-POS & $9.18 \_255.1710 \mathrm{~m} / \mathrm{z}$ & $M+K$ & $\mathrm{C}_{13} \mathrm{H}_{28} \mathrm{O}_{2}$ & 0.0004 & 1.4470 \\
\hline Hydroxydestruxin B & PM & $\alpha$-amino acid & 0.47 & RPC-NEG & 7.87_654.3665m/z & $\mathrm{M}+\mathrm{FA}-\mathrm{H}$ & $\mathrm{C}_{30} \mathrm{H}_{51} \mathrm{~N}_{5} \mathrm{O}_{8}$ & 0.0020 & 1.1840 \\
\hline Arecoline & SM & Alkaloid & 0.47 & HILIC-POS & 3.24_156.1022m/z & $\mathrm{M}+\mathrm{H}$ & $\mathrm{C}_{8} \mathrm{H}_{13} \mathrm{NO}_{2}$ & 0.0001 & 1.5429 \\
\hline Collettiside I & SM & Terpenoid & 0.46 & RPC-NEG & 8.16_613.3155m/z & $M+K-2 H$ & $\mathrm{C}_{33} \mathrm{H}_{52} \mathrm{O}_{8}$ & 0.0000 & 1.3730 \\
\hline Cyclocalopin F & SM & Phenol & 0.46 & HILIC-POS & 3.28_317.0976m/z & $\mathrm{M}+\mathrm{Na}$ & $\mathrm{C}_{15} \mathrm{H}_{18} \mathrm{O}_{6}$ & 0.0045 & 1.2504 \\
\hline (R)C(R)S-S-Propylcysteine sulfoxide & PM & $\alpha$-Amino acid & 0.46 & RPC-NEG & 1.85_200.0379m/z & $\mathrm{M}+\mathrm{Na}-2 \mathrm{H}$ & $\mathrm{C}_{6} \mathrm{H}_{13} \mathrm{NO}_{3} \mathrm{~S}$ & 0.0000 & 1.3730 \\
\hline Mabiogenin 3-[rhamnosyl-(1- > 6)-glucoside] & SM & Phenol & 0.45 & RPC-NEG & 7.28_817.4400m/z & $\mathrm{M}+\mathrm{Na}-2 \mathrm{H}$ & $\mathrm{C}_{42} \mathrm{H}_{68} \mathrm{O}_{14}$ & 0.0030 & 1.1630 \\
\hline Jurubine & SM & Terpenoid & 0.45 & RPC-NEG & 8.76_630.3815m/z & $\mathrm{M}+\mathrm{Cl}$ & $\mathrm{C}_{33} \mathrm{H}_{57} \mathrm{NO}_{8}$ & 0.0000 & 1.3710 \\
\hline Neotussilagine & SM & Alkaloid & 0.43 & HILIC-POS & $9.24 \_241.1557 \mathrm{~m} / \mathrm{z}$ & $\mathrm{M}+\mathrm{ACN}+\mathrm{H}$ & $\mathrm{C}_{10} \mathrm{H}_{17} \mathrm{NO}_{3}$ & 0.0001 & 1.5455 \\
\hline Pubescenol & SM & Terpenoid & 0.41 & RPC-NEG & 8.81_509.2678m/z & $\mathrm{M}+\mathrm{Cl}$ & $\mathrm{C}_{28} \mathrm{H}_{42} \mathrm{O}_{6}$ & 0.0000 & 1.3310 \\
\hline 3-(1-Hydroxymethyl-1-propenyl)pentanedioic acid & PM & Lipid & 0.41 & HILIC-POS & 4.83_220.1178m/z & $\mathrm{M}+\mathrm{NH}_{4}$ & $\mathrm{C}_{9} \mathrm{H}_{14} \mathrm{O}_{5}$ & 0.0111 & 1.1490 \\
\hline $2^{\prime}$-Deoxymugineic acid & SM & Other & 0.40 & HILIC-POS & $24.18 \_304.1245 n$ & $\mathrm{M}+\mathrm{H}, \mathrm{M}+\mathrm{Na}, \mathrm{M}+\mathrm{K}$ & $\mathrm{C}_{12} \mathrm{H}_{20} \mathrm{~N}_{2} \mathrm{O}_{7}$ & 0.0002 & 1.4868 \\
\hline 7C-Aglycone & SM & Other & 0.40 & HILIC-POS & 3.89_299.1302m/z & $\mathrm{M}+\mathrm{H}$ & $\mathrm{C}_{18} \mathrm{H}_{18} \mathrm{O}_{4}$ & 0.0006 & 1.4171 \\
\hline Dihydroxyacetone phosphate & PM & Carbohydrate & 0.39 & HILIC-NEG & 29.21_204.9685m/z & $\mathrm{M}+\mathrm{Cl}$ & $\mathrm{C}_{3} \mathrm{H}_{7} \mathrm{O}_{6} \mathrm{P}$ & 0.0070 & 2.1330 \\
\hline 5-Hydroxymethyltolterodine & SM & Phenol & 0.38 & HILIC-POS & 3.93_383.2665m/z & $\mathrm{M}+\mathrm{ACN}+\mathrm{H}$ & $\mathrm{C}_{22} \mathrm{H}_{31} \mathrm{NO}_{2}$ & 0.0004 & 1.4523 \\
\hline
\end{tabular}


TABLE 5 | Continued

\begin{tabular}{|c|c|c|c|c|c|c|c|c|c|}
\hline Metabolites & Class & Subclass & FC (LK/NK) & Mode & Compound ID & Adducts & Formula & $P$-value & $\begin{array}{l}\text { Variable importance for } \\
\text { the projection score }\end{array}$ \\
\hline L-gamma-Glutamyl-S-allylthio-L-cysteine & PM & $\alpha$-Amino acid & 0.38 & RPC-NEG & 2.23_359.0125m/z & $M+K-2 H$ & $\mathrm{C}_{11} \mathrm{H}_{18} \mathrm{~N}_{2} \mathrm{O}_{5} \mathrm{~S}_{2}$ & 0.0050 & 1.1070 \\
\hline Pinostilbenoside & SM & Phenol & 2.37 & RPC-NEG & $1.99 \_441.0985 \mathrm{~m} / \mathrm{z}$ & $M+K-2 H$ & $\mathrm{C}_{21} \mathrm{H}_{24} \mathrm{O}_{8}$ & 0.0010 & 1.2480 \\
\hline Oleanolic acid 3-[glucosyl-(1- > 4)-xyloside] & SM & Terpenoid & 0.35 & RPC-NEG & 7.23_771.4352m/z & $\mathrm{M}+\mathrm{Na}-2 \mathrm{H}$ & $\mathrm{C}_{41} \mathrm{H}_{66} \mathrm{O}_{12}$ & 0.0030 & 1.1530 \\
\hline Sepiapterin & PM & Nucleotide & 0.34 & HILIC-POS & 4.77_260.0755m/z & $\mathrm{M}+\mathrm{Na}$ & $\mathrm{C}_{9} \mathrm{H}_{11} \mathrm{~N}_{5} \mathrm{O}_{3}$ & 0.0010 & 1.3840 \\
\hline Eupatilin & SM & Phenol & 0.33 & RPC-NEG & 12.65_365.0615m/z & $\mathrm{M}+\mathrm{Na}-2 \mathrm{H}$ & $\mathrm{C}_{18} \mathrm{H}_{16} \mathrm{O}_{7}$ & 0.0030 & 1.1700 \\
\hline Theasapogenol E & SM & Terpenoid & 0.31 & RPC-NEG & 8.29_541.2934m/z & $\mathrm{M}+\mathrm{K}-2 \mathrm{H}$ & $\mathrm{C}_{30} \mathrm{H}_{48} \mathrm{O}_{6}$ & 0.0000 & 1.4320 \\
\hline 1-Acetoxy-2-hydroxy-16-heptadecyn-4-one & PM & Lipid & 0.29 & HILIC-POS & 9.86_342.2639m/z & $\mathrm{M}+\mathrm{NH}_{4}$ & $\mathrm{C}_{19} \mathrm{H}_{32} \mathrm{O}_{4}$ & 0.0192 & 1.0771 \\
\hline Maltitol & PM & Carbohydrate & 0.27 & HILIC-POS & 19.59_345.1390m/z & $M+H$ & $\mathrm{C}_{12} \mathrm{H}_{24} \mathrm{O}_{11}$ & 0.0001 & 1.5399 \\
\hline Palmitic acid & PM & Lipid & 0.25 & HILIC-POS & 8.70_274.2743m/z & $\mathrm{M}+\mathrm{NH}_{4}$ & $\mathrm{C}_{16} \mathrm{H}_{32} \mathrm{O}_{2}$ & 0.0088 & 1.1764 \\
\hline 2-Aminodipyrido[1,2-a:3', $2^{\prime}$-d]imidazole & SM & Alkaloid & 0.25 & RPC-NEG & 2.30_219.0446m/z & $\mathrm{M}+\mathrm{Cl}$ & $\mathrm{C}_{10} \mathrm{H}_{8} \mathrm{~N}_{4}$ & 0.0000 & 1.5770 \\
\hline Phytosphingosine & PM & Lipid & 0.24 & HILIC-POS & 8.37_318.3015m/z & $\mathrm{M}+\mathrm{H}$ & $\mathrm{C}_{18} \mathrm{H}_{39} \mathrm{NO}_{3}$ & 0.0011 & 1.3781 \\
\hline 2-Hydroxy-3-(4-methoxyphenyl)propanoic acid & SM & Phenol & 0.24 & RPC-NEG & $2.27 \_217.0473 \mathrm{~m} / \mathrm{z}$ & $\mathrm{M}+\mathrm{Na}-2 \mathrm{H}$ & $\mathrm{C}_{10} \mathrm{H}_{12} \mathrm{O}_{4}$ & 0.0000 & 1.5730 \\
\hline Arginyl-leucine & PM & $\alpha$-Amino acid & 0.23 & HILIC-POS & 27.98_288.2036m/z & $\mathrm{M}+\mathrm{H}$ & $\mathrm{C}_{12} \mathrm{H}_{25} \mathrm{~N}_{5} \mathrm{O}_{3}$ & 0.0227 & 1.0535 \\
\hline Ganoderic acid Mf & SM & Terpenoid & 0.22 & RPC-NEG & 8.31_533.3278m/z & $\mathrm{M}+\mathrm{Na}-2 \mathrm{H}$ & $\mathrm{C}_{32} \mathrm{H}_{48} \mathrm{O}_{5}$ & 0.0010 & 1.2800 \\
\hline 1-Octene & SM & Other & 0.21 & HILIC-POS & $8.78 \_130.1590 \mathrm{~m} / \mathrm{z}$ & $\mathrm{M}+\mathrm{NH}_{4}$ & $\mathrm{C}_{8} \mathrm{H}_{16}$ & 0.0014 & 1.3547 \\
\hline Myristic acid & PM & Lipid & 0.14 & HILIC-POS & $9.15 \_246.2430 \mathrm{~m} / \mathrm{z}$ & $\mathrm{M}+\mathrm{NH}_{4}$ & $\mathrm{C}_{14} \mathrm{H}_{28} \mathrm{O}_{2}$ & 0.0077 & 1.1925 \\
\hline Cortolone-3-glucuronide & SM & Terpenoids & 0.12 & RPC-NEG & 8.76_523.2601m/z & $\mathrm{M}-\mathrm{H}_{2} \mathrm{O}-\mathrm{H}$ & $\mathrm{C}_{27} \mathrm{H}_{42} \mathrm{O}_{11}$ & 0.0110 & 1.0360 \\
\hline 6-Methyl 2-galloylgalactarate & PM & Carbohydrate & 0.10 & HILIC-POS & 12.77_394.0974m/z & $\mathrm{M}+\mathrm{NH}_{4}$ & $\mathrm{C}_{14} \mathrm{H}_{16} \mathrm{O}_{12}$ & 0.0000 & 1.6801 \\
\hline L-Phenylalanyl-L-proline & PM & $\alpha$-Amino acid & 0.10 & RPC-NEG & 8.29_523.2607m/z & $2 \mathrm{M}-\mathrm{H}$ & $\mathrm{C}_{14} \mathrm{H}_{18} \mathrm{~N}_{2} \mathrm{O}_{3}$ & 0.0050 & 1.1090 \\
\hline Medicagenic acid & SM & Terpenoid & 0.08 & RPC-NEG & 8.76_539.2786m/z & $M+K-2 H$ & $\mathrm{C}_{30} \mathrm{H}_{46} \mathrm{O}_{6}$ & 0.0000 & 1.3410 \\
\hline Desglucocoroloside & SM & Terpenoid & 0.08 & RPC-NEG & 8.18_539.2788m/z & $\mathrm{M}+\mathrm{Cl}$ & $\mathrm{C}_{29} \mathrm{H}_{44} \mathrm{O}_{7}$ & 0.0000 & 1.4800 \\
\hline N(6)-(Octanoyl)lysine & PM & $\alpha$-Amino acid & 0.06 & HILIC-POS & 28.71_295.1995m/z & $\mathrm{M}+\mathrm{Na}$ & $\mathrm{C}_{14} \mathrm{H}_{28} \mathrm{~N}_{2} \mathrm{O}_{3}$ & 0.0000 & 1.6709 \\
\hline Falcarindione & SM & Terpenoid & 0.05 & RPC-NEG & 8.33_557.2890m/z & $2 \mathrm{M}+\mathrm{FA}-\mathrm{H}$ & $\mathrm{C}_{17} \mathrm{H}_{20} \mathrm{O}_{2}$ & 0.0010 & 1.2260 \\
\hline Erythro-6,8-pentacosanediol & PM & Lipid & 0.04 & HILIC-POS & 8.05_423.3601m/z & $M+K$ & $\mathrm{C}_{25} \mathrm{H}_{52} \mathrm{O}_{2}$ & 0.0116 & 1.1430 \\
\hline 6-Hydroxydaidzein 4'-glucoside & SM & Phenol & 0.02 & HILIC-POS & 3.77_455.0921m/z & $\mathrm{M}+\mathrm{Na}$ & $\mathrm{C}_{21} \mathrm{H}_{20} \mathrm{O}_{10}$ & 0.0011 & 1.3765 \\
\hline
\end{tabular}

Significantly different metabolites were selected based on partial least squares discriminant analysis and volcano plots, all with $p<0.05$; variable importance for the projection scores $>1.0$ and FC $>2.0$. FC(LK/NK), fold change (LK vs. NK); PM, primary metabolite; SM, secondary metabolite. 


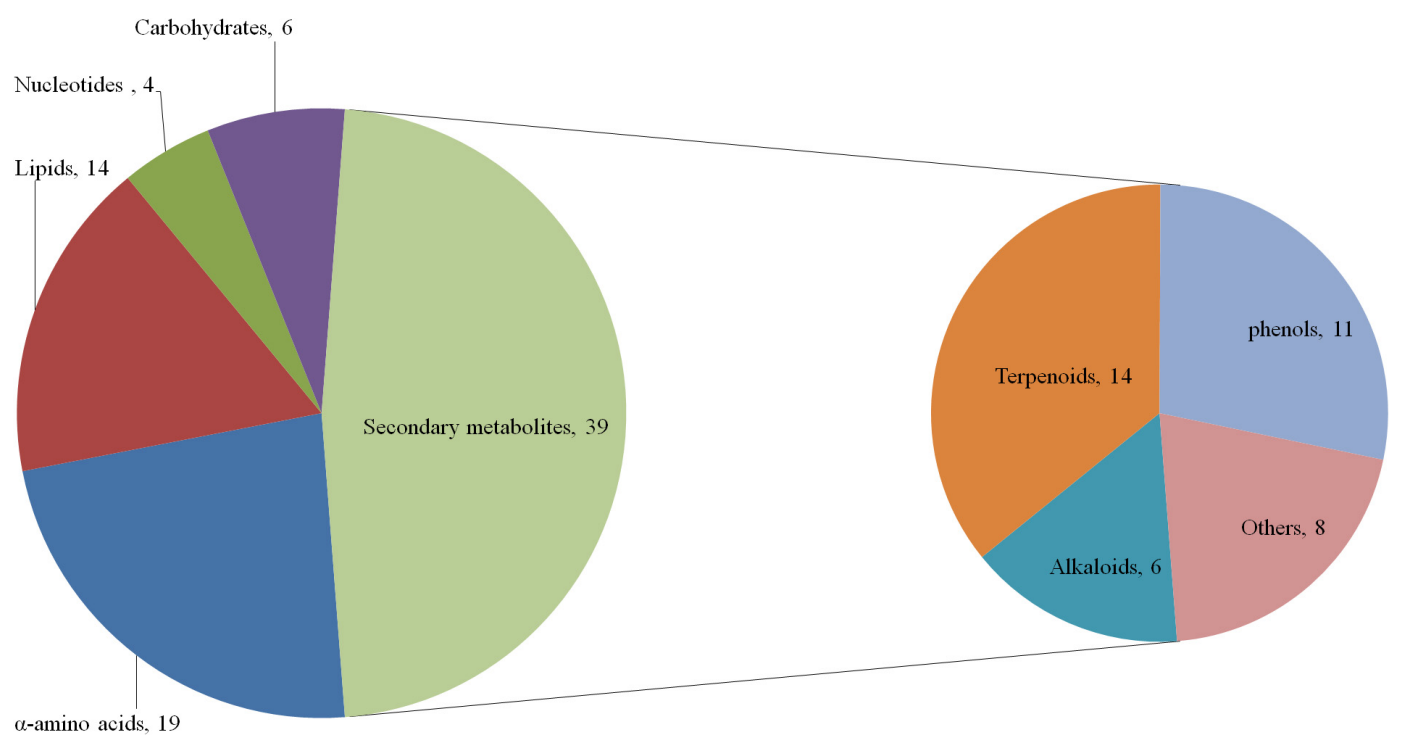

FIGURE 5 | Compound pie chart of primary and secondary metabolites based on 82 significant metabolites.

were 13:6 for $\alpha$-amino acids, 7:7 for lipids, 3:1 for nucleotides, and 2:4 for carbohydrates; those of 13 up-regulated and 26 downregulated secondary metabolites in the LK treatment were 2:4 for alkaloids, 2:12 for terpenoids, 4:7 for phenols, and 5:3 for others (Figure 6). These results show that LK stress promoted the accumulations of primary metabolites and inhibited the productions of secondary metabolites in the xylem sap of cotton.

\section{Metabolic Pathway Analyses}

The pathway impact plot (Figure 7) provides an overview of 26 metabolites that matched the KEGG pathways using MetaboAnalyst 4.0 online ${ }^{1}$. The results indicate that lysine biosynthesis and nicotinate and nicotinamide metabolism were the mainly pathways involved in the response to LK stress (red circles in the upper-right corner of the graph; more details can be found in Table 6). L-Aspartic acid $(\mathrm{FC}=4.04)$ is an important $\alpha$ amino acid, and it matched up to 10 pathways including amino acid synthesis and metabolism, nicotinate and nicotinamide metabolism, carbon fixation in photosynthetic organisms, and minoacyl-tRNA biosynthesis. Furthermore, both L-tryptophan $(\mathrm{FC}=2.20)$ and dihydroxyacetone phosphate $(\mathrm{FC}=0.39)$ matched six metabolic pathways.

\section{DISCUSSION}

\section{Changes in Morphology and Physiology of Cotton Seedlings Under LK Stress}

$\mathrm{K}$ is an inorganic element necessary for plant growth and development. K deficiency can lead to a decrease in plant metabolic substances such as free protein in the xylem sap, which leads to a thin morphology (Zhang et al., 2015a,b; Fontana et al.,

${ }^{1}$ www.metaboanalyst.ca
2020). This study confirmed such changes of morphology after 7 days of LK stress (Table 1) and additionally showed the changes in metabolism. Although the volume of xylem sap significantly increased under LK stress, this may have been due to a higher root pressure caused by a decrease in K content (Zhang Z. et al., 2016).

$\mathrm{K}^{+}$is the anti-anion needed for electroneutralization. A decrease in $\mathrm{K}^{+}$concentration in plant tissues and cells can lead to cation imbalance (Armengaud et al., 2009), which in the present study was reflected by the significant decrease in $\mathrm{pH}$ value caused by LK treatment (Table 2 ). Under LK stress, the inorganic ions with positive charge (e.g., $\mathrm{Na}^{+}, \mathrm{Mg}^{2+}, \mathrm{Fe}^{2+}$, $\mathrm{Zn}^{2+}$ ) decreased in the xylem sap (Table 2), and the decrease in the activities of protective enzymes such as SOD and POD indirectly led to the accumulation of toxic peroxides such as MDA (Table 3). Meanwhile, the concentration of $\mathrm{Ca}^{2+}$ as the secondary messenger in plant cells increased (Table 2), indicating that $\mathrm{Ca}^{2+}$ could be used as a response signal of cotton seedlings to LK stress (Girón-Calle and JayForman, 2000; Guo et al., 2013). To maintain charge balance under LK stress, plants enhance positively charged amino acids and inhibit negatively charged amino acids; these are strategies for plants to maintain charge balance under LK stress (Zeng et al., 2018). In this study, we observed that the contents of amino acid levels in the xylem sap significantly increased under LK stress $(\mathrm{pH}=5.41)$, and the FCs of positively charged L-histidine $(\mathrm{pI}=7.59)$ and L-tryptophan ( $\mathrm{pI}=5.89$ ) were higher than that of negatively charged L-aspartic acid ( $\mathrm{pI}=2.97$ ) (Table 5 ), which may have been caused by the requirement of charge balance.

\section{Changes in the Metabolome of Cotton Xylem Sap Under LK Stress}

The metabolome reflects the life activities that are happening at a certain moment, and it can directly reflect the impact of environmental changes on organisms (Dixon et al., 2002). The 


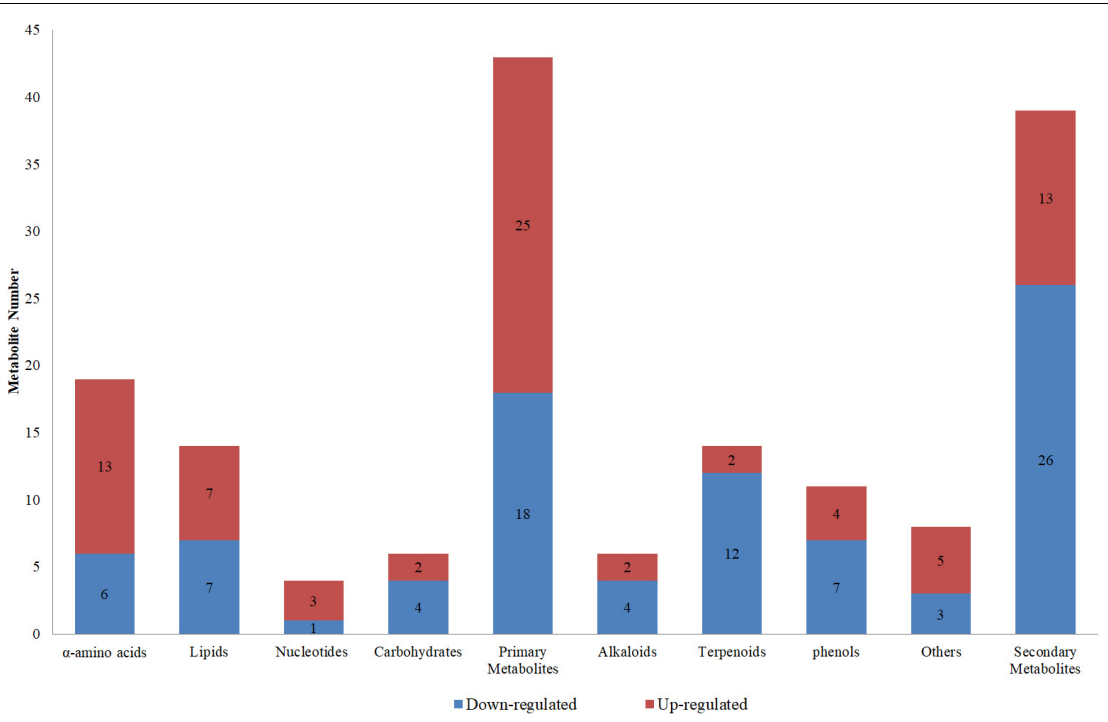

FIGURE 6 | Classifications of up- and down-regulated metabolites in the low-K treatment compared to controls.

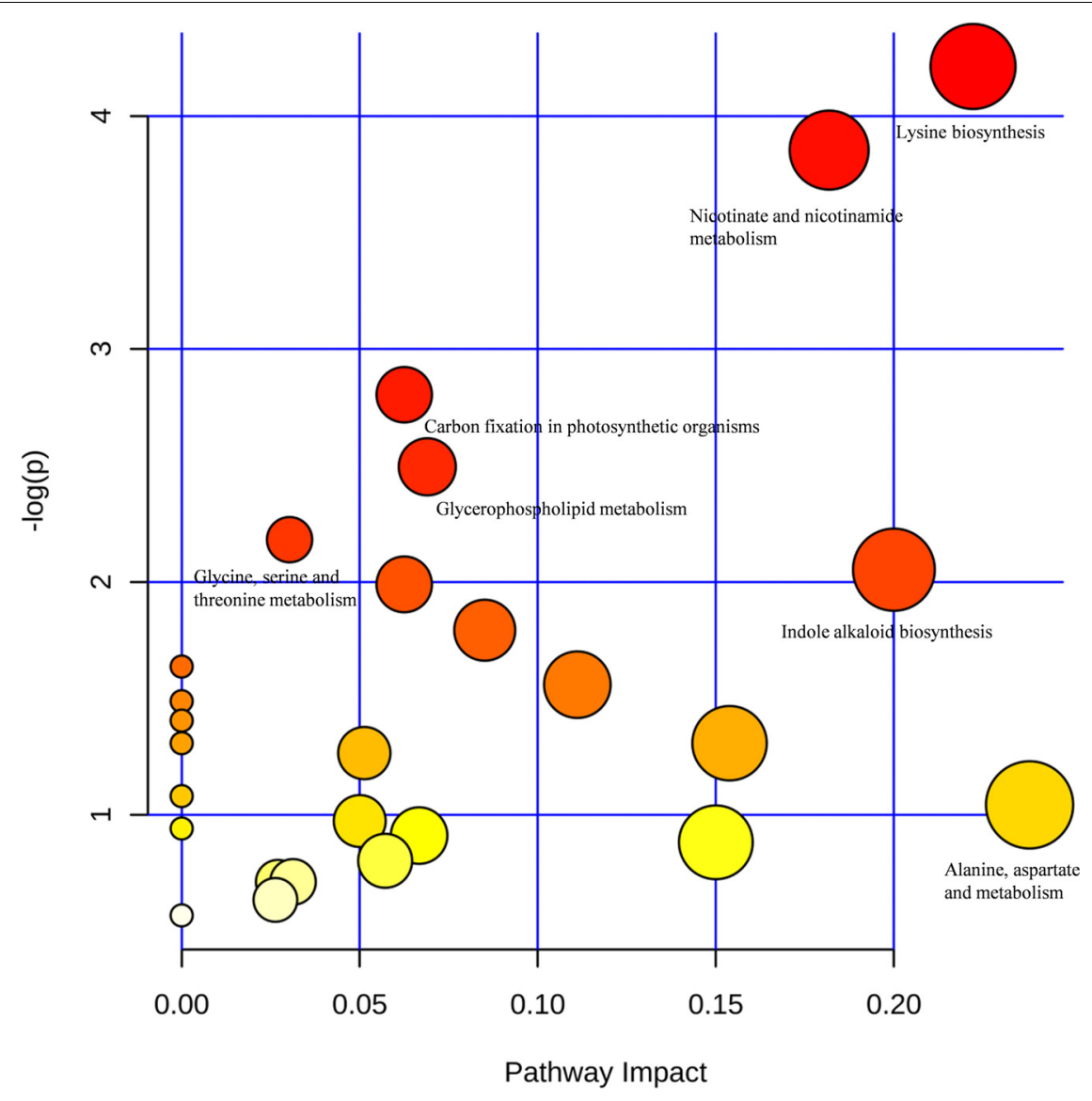

FIGURE 7 | Pathway impact plot of 26 matched Kyoto Encyclopedia of Genes and Genomes (KEGG) pathways: representation of the metabolites matching the KEGG pathways displayed according to their significance by pathway enrichment analyses ( $y$-axis) and impact factors by pathway topology analyses ( $x$-axis). The redder colors indicate lower $P$-values (higher $-\log _{e} P, e \approx 2.71828$ ), and the larger circles represent higher impact factors. The lower $P$-values and the larger impact factor indicate pathways that were greatly influenced. The pathway impact factor is calculated by the cumulative percentage of the matched metabolites, and the maximum impact factor of each pathway is 1. 
TABLE 6 | Overview of the pathway analyses of 26 metabolites matching the Kyoto Encyclopedia of Genes and Genomes pathways.

\begin{tabular}{|c|c|c|c|c|c|}
\hline No. & Pathway name & Total & Hits & Involved metabolites & Impact \\
\hline 1 & Alanine, aspartate, and glutamate metabolism & 22 & 1 & L-aspartic acid & 0.24 \\
\hline 2 & Lysine biosynthesis & 10 & 2 & L-aspartic acid, tetrahydrodipicolinate & 0.22 \\
\hline 3 & Indole alkaloid biosynthesis & 7 & 1 & L-tryptophan & 0.20 \\
\hline 4 & Nicotinate and nicotinamide metabolism & 12 & 2 & L-Aspartic acid, dihydroxyacetone phosphate & 0.18 \\
\hline 5 & Fructose and mannose metabolism & 16 & 1 & Dihydroxyacetone phosphate & 0.15 \\
\hline 6 & Tryptophan metabolism & 27 & 1 & L-tryptophan & 0.15 \\
\hline 7 & Beta-alanine metabolism & 12 & 1 & L-aspartic acid & 0.11 \\
\hline 8 & Pyrimidine metabolism & 38 & 2 & dCMP, thymidine & 0.09 \\
\hline 9 & Glycerophospholipid metabolism & 25 & 2 & Glycerophosphocholine, dihydroxyacetone phosphate & 0.07 \\
\hline 10 & Galactose metabolism & 26 & 1 & Sucrose & 0.07 \\
\hline 11 & Carbon fixation in photosynthetic organisms & 21 & 2 & L-aspartic acid, dihydroxyacetone phosphate & 0.06 \\
\hline 12 & Aminoacyl-tRNA biosynthesis & 67 & 3 & L-histidine, L-aspartic acid, L-tryptophan & 0.06 \\
\hline 13 & Starch and sucrose metabolism & 30 & 1 & Sucrose & 0.06 \\
\hline 14 & Glucosinolate biosynthesis & 54 & 2 & Homomethionine, L-tryptophan & 0.05 \\
\hline 15 & Inositol phosphate metabolism & 24 & 1 & Dihydroxyacetone phosphate & 0.05 \\
\hline 16 & Cysteine and methionine metabolism & 34 & 1 & L-aspartic acid & 0.03 \\
\hline 17 & Glycine, serine, and threonine metabolism & 30 & 2 & L-aspartic acid, L-tryptophan & 0.03 \\
\hline 18 & Fatty acid metabolism & 34 & 1 & Palmitic acid & 0.03 \\
\hline 19 & Arginine and proline metabolism & 38 & 1 & L-aspartic acid & 0.03 \\
\hline 20 & Cyanoamino acid metabolism & 11 & 1 & L-aspartic acid & 0.00 \\
\hline 21 & Fatty acid elongation in mitochondria & 13 & 1 & Palmitic acid & 0.00 \\
\hline 22 & Fatty acid biosynthesis & 49 & 2 & Myristic acid, palmitic acid & 0.00 \\
\hline 23 & Histidine metabolism & 16 & 1 & L-Histidine & 0.00 \\
\hline 24 & Phenylalanine, tyrosine, and tryptophan biosynthesis & 21 & 1 & L-Tryptophan & 0.00 \\
\hline 25 & Glycolysis or gluconeogenesis & 25 & 1 & Dihydroxyacetone phosphate & 0.00 \\
\hline 26 & Biosynthesis of unsaturated fatty acids & 42 & 1 & Palmitic acid & 0.00 \\
\hline
\end{tabular}

metabolites of eight different biological samples were analyzed by HPLC-MS/MS under each treatment, and 82 metabolites with significant differences between the treatments were screened by volcano plots (Figure 3 and Table 5).

\section{Changes in Primary Metabolites of Cotton Xylem Sap Under LK Stress}

Carbohydrate metabolism plays a key role in primary metabolism in plants, provides energy for normal growth and development, and acts as a bridge in protein, fat, and nucleic acid metabolism (Rolland et al., 2006). Compared to controls, there were two significantly up-regulated carbohydrates (sucrose and mannitol) in the xylem sap of LK plants (Table 5). Sucrose can act as an osmotic regulator to generate osmotic pressure or as a substrate to produce energy, and it can also induce resistance to adverse conditions through signal transduction (Smeekens, 2000; Hanson et al., 2007). Mannitol is a sugar alcohol with six hydroxyl groups formed after the reduction of mannose. Sugar alcohols can improve the stress resistance of plants by regulating cell permeability and acting as freeradical scavengers (Tarczynski et al., 1993; Stoop et al., 1996; Geng et al., 2011); when they form complexes with nutrient elements such as calcium, they play an important role in vegetable and fruit production (Ding et al., 2015; Li et al., 2018). Mannitol levels are significantly increased under hightemperature stress in Poa pratensis (Du et al., 2011) and drought stress in Fraxinus excelsior xylem (Patonnier et al., 1999). Similarly, in our study, the sucrose and the mannitol levels in the xylem sap of cotton seedlings were significantly increased under LK stress, which might have been an adaptive change under K deficiency.

Besides carbohydrates, the levels of several other primary metabolites changed significantly under LK stress, including 19 amino acids, 14 lipids, and four nucleic acids (Figure 6). These metabolites are involved in tricarboxylic acid cycle, glycolysis, phospholipid/fatty acid synthesis, nitrogen assimilation, and shikimic acid pathway (Table 6), which are precursors of secondary metabolism. Among them, the levels of some metabolites found in cell membrane including three cholines (glycerophosphatecholine, 2-hexenylcholine, and caproylcholine) and desglucocoroloside and a variety of $\alpha$-amino acids and their derivatives (dipeptides, such as arginyl-leucine, asparaginyl-valine, cysteinyl-histidine, glycylhydroxyproline, histidinyl-methionine, and serinyl-threonine) were significantly increased under LK stress (Tables 5, 6), indicating that protein was metabolized abnormally, resulting in damage to cell membranes.

It is noteworthy that glycerophosphocholine is the major glycerophospholipid in eukaryotic cellular membranes $(>50 \%$ of all phospholipids) where it makes up the bulk of the bilayer with other lipid classes (e.g., cholesterol) dispersed for fluidity. Glycerophosphocholine is also an important precursor for other 
lipids, such as sphingomyelin or choline plasmalogens as well as the second messengers diacylglycerol, (lyso-)phosphatidic acid, and arachidonic acid (Triebl, 2016). The dramatic upregulation of glycerophosphocholine under LK stress suggests that it can act as an important signal for root-shoot communication like acetylcholine (Wang et al., 2003).

\section{Changes in Secondary Metabolites of Cotton Xylem Sap Under LK Stress}

Generally, the well-known anti-abiotic stress metabolites include proline, free sugars, free proteins, and antioxidant enzymes (Han et al., 2013; Guo et al., 2018). However, these resistance markers almost are secondary metabolites produced by plants that help fight against various stresses in nature (Tiwari and Rana, 2015). At present, there are more than 2,140,000 known secondary metabolites produced in the plant kingdom (Thirumurugan et al., 2018). Plants generally open a series of secondary metabolic pathways under stress, among which the phenylalanine metabolic pathway that produces flavonoids, lignin, alkaloids, and other resistant substances is the most important (Dixon et al., 2002).

A total of 26 secondary metabolites belonging to phenols, terpenoids, alkaloids, and other categories significantly decreased under LK stress, including 12 terpenoids (Figure 6). Terpenoids derived from carbon metabolism are volatile ( $\mathrm{Wu}$ et al., 2017), and their significant downregulation under LK stress reduces the loss of carbon source metabolites to maintain basic growth needs. Among them, desglucocoroloside, which is polycyclic triterpenoid, is not only an antioxidant (Bosak et al., 2008) but also a membrane stabilizer (Wishart et al., 2017), and its significant downregulation (Table 5) may reflect a weaker antioxidant capacity under LK stress compared to controls. Furthermore, 6-hydroxydaidzein $4^{\prime}$-glucoside, an O-glycosylated derivative of isoflavonoids, which is a natural product derived from 3-phenylchromen-4-one, was the most down-regulated secondary metabolite (Table 5), although there has been no report on the physiological effects of 6-hydroxydaidzein $4^{\prime}$-glucoside, its synthetic precursors, and isoflavonoid properties, indicating that it has an antioxidant function (Castellano and Torrens, 2015).

In addition, 13 secondary metabolites were significantly upregulated under LK stress (Figure 6). Among them, gynocardin and mintsulfide were up-regulated by 14.72 and 12.29 times, respectively, compared to NK (Table 5). Gynocardin is the first cyclopentenoid glycoside discovered in plants, and its chemical structure has been determined (Webber and Miller, 2008), and cyclopentenone is the glycoside ligand of gynocardin, containing a cyanide group toxic to plants, which might be one of the reasons why the total length, surface area, and volume of roots significantly decreased under LK stress (Siegieñ and Bogatek, 2006). In Pangium edule Reinw, soil condition affects the content of gynocardin (Yuningsih, 2008). Mintsulfide, as a volatile metabolite that consumes nutrients, is an enol ester of sulfurcontaining sesquiterpene, which might be a signal substance produced by cotton seedlings in response to LK stress (Drahl, 2014). However, because some of the secondary metabolites detected were newly discovered from cotton, their structures, roles, and functions need to be further identified.

\section{Metabolic Pathway of Cotton Xylem Sap Under LK Stress}

The metabolic pathway analyses indicated that 10 principal pathways of the metabolites in response to LK stress involved L-aspartic acid, including lysine biosynthesis and nicotinate and nicotinamide metabolism (Table 6). Tetrahydrodipicolinate (THDP) and L-aspartic acid were strongly up-regulated and are involved in lysine biosynthesis. L-aspartic acid was synthesized by the reaction of L-aspartic acid to diaminopimelate, and then THDP was created to synthesize lysine (Griffin et al., 2012). Lysine is not only an essential component of all proteins but also an important signal amino acid, which plays an important part in regulating plant growth and the response to the environment (Galili et al., 2001; Zhang X. et al., 2016). Furthermore, the inhibition pathway of lysine biosynthesis provides an attractive target for the development of new herbicides. In the most primitive pathway of nicotinate biosynthesis, quinolinic acid, which is a precursor of $\mathrm{NAD}^{+}$, is synthesized from L-aspartic acid and dihydroxyacetone phosphate (Cleaves and Miller, 2001), and the latter was significantly down-regulated under LK stress. In addition, L-aspartic acid is involved in the metabolism of alanine, aspartate, and glutamate, and L-tryptophan is involved in the biosynthesis of indole alkaloids; all of these are also worthy of attention.

\section{CONCLUSION}

K deficiency significantly altered ion uptake and organic substance metabolism and further caused changes in the physiology and the morphology levels in cotton. In detail, $\mathrm{K}$ deficiency disturbed cation absorption that caused acidity in the xylem sap. $\mathrm{K}$ deficiency also reduced the antioxidant capacity of cotton cells and further resulted in membrane damage that altered the primary and the secondary metabolism in cells, including decreased content of free sugar and soluble proteins as well as increased content of amino acids. Our results also show that cotton plants could positively adapt to $\mathrm{K}$ deficiency, which was evidenced by several observed phenomena that included the following: (1) more sucrose and mannitol were generated to balance the osmosis pressure caused by the $\mathrm{K}$ deficiency, (2) the reduction of volatile terpenoids reduced carbon loss to maintain basic growth, (3) compared with sufficient potassium, the glycerophosphocholine in the xylem sap was increased by nearly 29 -folds, indicating that the roots coordinated the growth of leaves and roots under K deficiency.

\section{DATA AVAILABILITY STATEMENT}

The original contributions presented in the study are included in the article/supplementary material, further inquiries can be directed to the corresponding author/s. 


\section{AUTHOR CONTRIBUTIONS}

$\mathrm{XZ}, \mathrm{GW}$, and ZZ designed the study and wrote the manuscript. $\mathrm{XZ}$ analyzed xylem sap metabolites quantification, classification, and related pathways. GW, HX, JZ, QW, and ZZ cultivated cotton seedlings, collected xylem sap, and determined the morphological indexes of cotton seedlings and the physiological indicators of xylem sap. BZ improved the manuscript. All co-authors finally approved the manuscript for submission.

\section{REFERENCES}

Aksu, G., and Altay, H. (2020). The effects of potassium applications on drought stress in sugar beet: part I. Sugar beet quality components. J. Sci. Perspect. 4, 157-168. doi: 10.26900/JSP.4.013

Anderson, J. R., Phelan, M. M., Rubio-Martinez, L. M., Fitzgerald, M. M., and Peffers, M. J. (2020). Optimisation of synovial fluid collection and processing for NMR metabolomics and LC-MS/MS proteomics. J. Proteome Res. 19, 2585-2597. doi: 10.1021/acs.jproteome.0c00035

Andrea, T., Nguyet, T. A., Giacomo, N., Di Mambro, R., Michele, P., Sacchi, G. A., et al. (2020). The calcineurin $\beta$-like interacting protein kinase CIPK25 regulates potassium homeostasis under low oxygen in Arabidopsis. J. Exp. Bot. 71, 2678-2689. doi: 10.1093/jxb/eraa004

Armengaud, P., Sulpice, R., Miller, A. J., Stitt, M., Amtmann, A., Gibon, Y., et al. (2009). Multilevel analysis of primary metabolism provides new insights into the role of potassium nutrition for glycolysis and nitrogen assimilation in Arabidopsis roots. Plant Physiol. 150, 772-785. doi: 10.1104/pp.108.133629

Bednarz, C. W., and Oosterhuis, D. M. (1999). Physiological changes associated with potassium deficiency in cotton. J. Plant Nutr. 22, 303-313. doi: 10.1080/ 01904169909365628

Bosak, T., Losick, R. M., and Pearson, A. (2008). A polycyclic terpenoid that alleviates oxidative stress. Proc. Natl. Acad. Sci. U.S.A. 105, 6725-6729. doi: 10.1073/pnas.0800199105

Bradford, M. M. (1976). A rapid and sensitive method for the quantitation of microgram quantities of protein utilizing the principle of proteindye binding. Anal. Biochem. 72, 248-254. doi: 10.1016/0003-2697(76)90 527-3

Cakmak, I., Hengeler, C., and Marschner, H. (1994). Changes in phloem export of sucrose in leaves in response to phosphorus, potassium and magnesium deficiency in bean plants. J. Exp. Bot. 45, 1251-1257. doi: 10.1093/jxb/45.9.1251

Castellano, G., and Torrens, F. (2015). Quantitative structure-antioxidant activity models of isoflavonoids: a theoretical study. Intern. J. Mol. Sci. 16, 12891-12906. doi: 10.3390/ijms160612891

Chai, M., Chen, Y., Xuan, R., Ma, J., and Wang, T. (2018). Preparation of attapulgite nanoparticles-based hybrid monolithic column with covalent bond for hydrophilic interaction liquid chromatography. Talanta 189, 397-403. doi: 10.1016/j.talanta.2018.07.039

Chatterjee, R., Davenport, C. A., Kwee, L., D’Alessio, D., and Shah, S. H. (2020). Preliminary evidence of effects of potassium chloride on a metabolomic path to diabetes and cardiovascular disease. Metabolomics 16:75. doi: 10.1007/s11306020-01696-w

Chen, G., Feng, H., Hu, Q., Qu, H., Chen, A., Xu, G., et al. (2015). Improving rice tolerance to potassium deficiency by enhancing Os HAK 16p: WOX 11controlled root development. Plant Biotechnol. J. 13, 833-848. doi: 10.1111/PBI. 12320

Chen, G., Zhang, Y., Ruan, B., Guo, L., Zeng, D., Gao, Z., et al. (2018). OsHAK1 controls the vegetative growth and panicle fertility of rice by its effect on potassium-mediated sugar metabolism. Plant Sci. 274, 261-270. doi: 10.1016/ j.plantsci.2018.05.034

Chérel, I., and Gaillard, I. (2019). The complex fine-tuning of K? fluxes in plants in relation to osmotic and ionic abiotic stresses. Intern. J. Mol. Sci. 20:715. doi: 10.3390/ijms20030715

Cleaves, H. J., and Miller, S. L. (2001). The nicotinamide biosynthetic pathway is a by-product of the RNA world. J. Mol. Evol. 52, 73-77. doi: 10.1007/ S002390010135

\section{FUNDING}

This research was supported by the Program for Innovative Research Team (in Science and Technology) in University of Henan Province (21IRTSTHN023), the National Natural Science Foundation of China (31571600), and the Key Scientific Research Foundation of the Higher Education Institutions of Henan Province (21A210005).

Coskun, D., Britto, D. T., and Kronzucker, H. J. (2017). The nitrogen-potassium intersection: membranes, metabolism, and mechanism. Plant Cell Environ. 40, 2029-2041. doi: 10.1111/pce.12671

Ding, S. S., Li, Y., Yuan, L., Zhao, B. Q., Lin, Z. A., Li, J., et al. (2015). Effects of small molecular organics chelated calcium fertilizer on cherry tomato yield,quality and nutrients absorption. Soil Fertiliz. Sci. China 15, 61-66.

Dixon, R. A., Achnine, L., Kota, P., Liu, C. J., Reddy, M. S. S., Wang, L., et al. (2002). The phenylpropanoid pathway and plant defence-a genomics perspective. Mol. Plant Pathol. 3, 371-390. doi: 10.1046/j.1364-3703.2002.00131.x

Drahl, C. (2014). Sulfide signal in sight. Chem. Eng. News 91:10. doi: 10.1021/CEN09116-NOTW7

Du, H., Wang, Z., Yu, W., Liu, Y., and Huang, B. (2011). Differential metabolic responses of perennial grass Cynodon transvaalensis $\times$ Cynodon dactylon (C4) and Poa Pratensis (C3) to heat stress. Physiol. Plant 141, 251-264. doi: 10.1111/ j.1399-3054.2010.01432.x

Feussner, K., and Feussner, I. (2019). Comprehensive LC-MS-based metabolite fingerprinting approach for plant and fungal-derived samples. Methods Mol. Biol. 1978, 167-185. doi: 10.1007/978-1-4939-9236-2_11

Fontana, J. E., Wang, G., Sun, R., Xue, H., Li, Q., Liu, J., et al. (2020). Impact of potassium deficiency on cotton growth, development and potential microRNAmediated mechanism. Plant Physiol. Biochem. 153, 72-80. doi: 10.1016/j.plaphy. 2020.05.006

Galili, G., Tang, G., Zhu, X., and Gakiere, B. (2001). Lysine catabolism: a stress and development super-regulated metabolic pathway. Curr. Opin. Plant Biol. 4, 261-266. doi: 10.1016/S1369-5266(00)00170-9

Geng, H., Wang, S., Guo, L., and Han, X. D. (2011). Effect of mannitol on wheat germination and seedling growth under seawater stress. Genom. Appl. Biol. 30, 218-223. doi: 10.3969/gab.030.000218

Gika, H. G., Theodoridis, G. A., Wingate, J. E., and Wilson, I. D. (2007). Withinday reproducibility of an HPLC-MS-based method for metabonomic analysis: application to human urine. J. Proteome Res. 6, 3291-3303. doi: 10.1021/ PR070183P

Girón-Calle, J., and JayForman, H. (2000). "Cell Ca2+ in signal transduction: modulation in oxidative stress," in Antioxidant and Redox Regulation of Genes, eds Y. F. Wang and A. Sarai (London: Academic Press), 105-127. doi: 10.1016/ B978-012636670-9/50007-6

Gorrochategui, E., Jaumot, J., Lacorte, S., and Tauler, R. (2016). Data analysis strategies for targeted and untargeted LC-MS metabolomic studies: overview and workflow. Trends Analyt. Chem. 82, 425-442. doi: 10.1016/j.trac.2016.07. 004

Green, K. A., Berry, D., Feussner, K., Eaton, C. J., Ram, A., Mesarchi, C. H., et al. (2020). Lolium perenne apoplast metabolomics for identification of novel metabolites produced by the symbiotic fungus Epichloë festucae. New Phytologist 227, 559-571. doi: 10.1111/nph.16528

Griffin, M. D. W., Billakanti, J. M., Wason, A., Keller, S., Mertens, H. D. T., Atikson, S. C., et al. (2012). Characterisation of the first enzymes committed to lysine biosynthesis in Arabidopsis thaliana. PLoS One 7:e40318. doi: 10.1371/journal. pone. 0040318

Guo, T., Dai, J., and Zhu, M. (2013). Effects of CaSignal inhibitors on heffluxes by ectomycorrhizal fungi under potassium stress. Entia Silvae Sin. 49, 97-100. doi: 10.11707/j.1001-7488.20131214

Guo, Y. Y., Yu, H. Y., Yang, M. M., Kong, D. S., and Zhang, Y. J. (2018). Effect of drought stress on lipid peroxidation, osmotic adjustment and antioxidant enzyme activity of leaves and roots of Lycium ruthenicum Murr. Seedling. Russian J. Plant Physiol. 65, 244-250. doi: 10.1134/S1021443718020127 
Hawkesford, M., Horst, W., Kichey, T., Lambers, H., Schjoerring, J., Skrumsager Moller, I., et al. (2012). "Functions of macronutrients," in Functions of Macronutrients, ed. P. Marschner, 3rd Edn (Sydney: Academic Press), 135-189. doi: 10.1016/B978-0-12-384905-2.00006-6

Han, Y., Fan, S., Zhang, Q., and Wang, Y. (2013). Effect of heat stress on the MDA, proline and soluble sugar content in leaf lettuce seedlings. Agric. Sci. 4, 112-115. doi: 10.4236/as.2013.45B021

Hanson, J., Hanssen, M., Wiese, A., Hendriks, M. M. W. B., and Smeekens, S. (2007). The sucrose regulated transcription factor bZIP11 affects amino acid metabolism by regulating the expression of ASPARAGINE SYNTHETASE1 and PROLINE DEHYDROGENASE2. Plant J. 53, 935-949. doi: 10.1111/J.1365313X.2007.03385.X

Hasanuzzaman, M., Bhuyan, M., Nahar, K., Hossain, M., Mahmud, J., Hossen, S., et al. (2018). Potassium: a vital regulator of plant responses and tolerance to abiotic stresses. Agronomy 8:31. doi: 10.3390/agronomy8030031

Hong, J., Yang, L., Zhang, D., and Shi, J. (2016). Plant metabolomics: an indispensable system biology tool for plant science. Intern. J. Mol. Sci. 17:767. doi: 10.3390/ijms17060767

Hosseini, S., Maillard, A., Hajirezaei, M., Ali, N., Schwarzenberg, A., et al. (2017). Induction of barley silicon transporter HvLsi1 and HvLsi2, increased silicon concentration in the shoot and regulated starch and ABA homeostasis under osmotic stress and concomitant potassium deficiency. Front. Plant Sci. 8:1359. doi: 10.3389/fpls.2017.01359

Hu, W., Coomer, T. D., Loka, D. A., Oosterhuis, D. M., and Zhou, Z. (2017). Potassium deficiency affects the carbon-nitrogen balance in cotton leaves. Plant Physiol. Biochem. 115, 408-417. doi: 10.1016/j.plaphy.2017.04.005

Hu, W., Lv, X., Yang, J., Chen, B., Zhao, W., Meng, Y., et al. (2016). Effects of potassium deficiency on antioxidant metabolism related to leaf senescence in cotton (Gossypium hirsutum L.). Field Crops Res. 191, 139-149. doi: 10.1016/j. fcr.2016.02.025

Irchhaiya, R., Kumar, A., Gupta, N., Kumar, S., Gupta, N., Gupta, N., et al. (2015). Metabolites in plants and its classification. World J. Pharm. Pharm. Sci. 4, 287-305.

Jungers, J. M., Kaiser, D. E., Lamb, J. F. S., Lamb, J. A., and Sheaffer, C. C. (2019). Potassium fertilization affects alfalfa forage yield, nutritive value, root traits, and persistence. Agron. J. 111, 2843-2852. doi: 10.2134/agronj2019.01.0011

Koch, M., Busse, M., Naumann, M., Jákli, B., Smit, I., Cakmak, I., et al. (2018). Differential effects of varied potassium and magnesium nutrition on production and partitioning of photoassimilates in potato plants. Physiol. Plant 166, 921935. doi: 10.1111/ppl.12846

Li, B., Wang, Y., Zhang, Z., Wang, B., Eneji, A. E., Duan, L., et al. (2012). Cotton shoot plays a major role in mediating senescence induced by potassium deficiency. J. Plant Physiol. 169, 327-335. doi: 10.1016/j.jplph.2011.10.009

Li, H. F., He, D. L., Fu, J. J., Wang, K. D., and Yang, X. J. (2018). Screening test of water-soluble fertilizers for watermelon (Citrullus lanatus). Agric. Biotechnol. 7, 136-138. doi: 10.19759/j.cnki.2164-4993.2018.06.033

Li, J., Nie, J. Y., and Li, H. F. (2008). On determination conditions for total polyphenols in fruits and its derived products by Folin-phenol methods. Intern. J. Fruit Ence 25, 126-131. doi: 10.3724/SP.J.1148.2008.00259

Li, X. X., and Li, J. Z. (2013). Determination of the content of soluble sugar in sweet corn with optimized anthrone colorimetric method. Storage Process. 13, 24-27. doi: 10.3969/j.issn.1009-6221.2013.04.006

Lu, Z., Lu, J., Hu, W., Ren, T., Zhu, C., Cong, R., et al. (2019). Impact of K deficiency on leaves and siliques photosynthesis via metabolomics in Brassica napus. Environ. Exp. Bot. 158, 89-98. doi: 10.1016/j.envexpbot.2018.11.008

Lurie, I. S., Li, L., and Toske, S. G. (2011). Hydrophilic interaction chromatography of seized drugs and related compounds with sub $2 \mu \mathrm{m}$ particle columns. J. Chromatogr. A 1218, 9336-9344. doi: 10.1016/j.chroma.2011.10.067

Ma, T., Wu, W., and Wang, Y. (2012). Transcriptome analysis of rice root responses to potassium deficiency. BMC Plant Biol. 12:161. doi: 10.1186/1471-2229-12161

Mari, A., Montoro, P., D’Urso, G., Macchia, M., Pizza, C., Piacente, S., et al. (2015). Metabolic profiling of Vitex agnus castus leaves, fruits and sprouts: analysis by LC/ESI/(QqQ)MS and (HR) LC/ESI/(Orbitrap)/MSn. J. Pharm. Biomed. Anal. 102, 215-221. doi: 10.1016/j.jpba.2014.09.018

Pan, Y., Lu, Z., Lu, J., Li, X., Cong, R., Ren, T., et al. (2017). Effects of low sink demand on leaf photosynthesis under potassium deficiency. Plant Physiol. Biochem. 113, 110-121. doi: 10.1016/j.plaphy.2017.01.027
Patonnier, M. P., Peltier, J. P., and Marigo, G. (1999). Drought-induced increase in xylem malate and mannitol concentrations and closure of Fraxinus excelsior L, Stomata. J. Exper. Bot. 50, 1223-1229. doi: 10.1093/JXB/50.336.1223

Peng, B., Li, H., and Peng, X. (2015). Functional metabolomics: from biomarker discovery to metabolome reprogramming. Protein Cell 6, 628-637. doi: 10.1007/ s13238-015-0185-x

Pettigrew, W. T. (1999). Potassium deficiency increases specific leaf weights and leaf glucose levels in field-grown cotton. Agron. J. 91, 962-968. doi: 10.2134/ agronj1999.916962x

Prabakaran, M., Chung, I., Son, N., Chi, H., Kim, S., Yang, Y.-J., et al. (2018). Analysis of selected phenolic compounds in organic, pesticide-free, conventional rice (Oryza sativa L.) using LC-ESI-MS/MS. Molecules 24:67. doi: 10.3390/molecules24010067

Ren, X. L., Li, L. Q., Xu, L., Guo, Y. S., and Lu, L. M. (2016). Identification of low potassium stress-responsive proteins in tobacco (Nicotiana tabacum) seedling roots using an iTRAQ-based analysis. Genet. Mol. Res. 15, 1-13. doi: 10.4238/gmr.15038573

Rolland, F., Baena-Gonzalez, E., and Sheen, J. (2006). Sugar sensing and signaling in plants: Conserved and novel mechanisms. Annu. Rev. Plant Biol. 57, 675-709. doi: 10.1146/annurev.arplant.57.032905.105441

Ronny, V. L. J., Arends, D., Li, Y., Willems, L. A. J., Keurentjes, J. J. B., Ligterink, W., et al. (2013). Identifying genotype-by-environment interactions in the metabolism of germinating Arabidopsis seeds using generalized genetical genomics. Plant Physiol. 162, 553-566. doi: 10.1104/pp.113.216176

Rukmini, M. S., D’Souza, B., and D’Souza, V. (2004). Superoxide dismutase and catalase activities and their correlation with malondialdehyde in schizophrenic patients. Indian J. Clin. Biochem. 19, 114-118. doi: 10.1007/BF02894268

Sangster, T., Major, H., Plumb, R., Wilson, A. J., and Wilson, I. D. (2006). A pragmatic and readily implemented quality control strategy for HPLC-MS and GC-MS-based metabonomic analysis. Analyst 131, 1075-1078. doi: 10.1039/ b604498k

Shimizu, T., Watanabe, M., Fernie, A. R., and Tohge, T. (2018). Targeted LC-MS analysis for plant secondary metabolites. Methods Mol. Biol. 1778, 171-181. doi: 10.1007/978-1-4939-7819-9_12

Siegieñ, I., and Bogatek, R. (2006). Cyanide action in plants - from toxic to regulatory. Acta Physiol. Plant. 28, 483-497. doi: 10.1007/BF027 06632

Smeekens, S. (2000). Sugar-induced signal transduction in plants. Annu. Rev. Plant Physiol. Plant Mol. Biol. 51, 49-81. doi: 10.1146/annurev.arplant. 51.1.49

Stoop, J. M. H., Williamson, J. D., and Pharr, D. M. (1996). Mannitol metabolism in plants: a method for coping with stress. Trends Plant Sci. 1, 139-144. doi: 10.1016/S1360-1385(96)80048-3

Sun, S. W., Lin, Y. C., Weng, Y. M., and Chen, M. J. (2006). Efficiency improvements on ninhydrin method for amino acid quantification. J. Food Composit. Analys. 19, 112-117. doi: 10.1016/j.jfca.2005.04.006

Sung, J., Lee, S., Lee, Y., Ha, S., Song, B., Kim, T., et al. (2015). Metabolomic profiling from leaves and roots of tomato (Solanum lycopersicum L.) plants grown under nitrogen, phosphorus or potassium-deficient condition. Plant Sci. 241, 55-64. doi: 10.1016/j.plantsci.2015.09.027

Taraji, M., Haddad, P. R., Amos, R. I. J., Talebi, M., and Pohl, C. (2018). Chemometric-assisted method development in hydrophilic interaction liquid chromatography: a review. Analyt. Chim. Acta 1000, 20-40. doi: 10.1016/j.aca. 2017.09.041

Tarczynski, M. C., Jensen, R. G., and Bohnert, H. J. (1993). Stress protection of transgenic tobacco by production of the osmolyte mannitol. Science 259, 508-510. doi: 10.1126/science.259.5094.508

Thirumurugan, D., Cholarajan, A., Raja, S. S. S., and Vijayakumar, R. (2018). "An introductory chapter: secondary metabolites," in Secondary Metabolites Sources and Applications, eds R. Vijayakumar and S. S. S. Raja (New York, NY: IntechOpen), doi: 10.5772/intechopen.79766

Thomason, K., Babar, A., Erickson, J. E., Mulvaney, M., Beecher, C., MacDonald, G., et al. (2018). Comparative physiological and metabolomics analysis of wheat (Triticum aestivum L.) following post-anthesis heat stress. PLoS One 13:e197919. doi: 10.1371/JOURNAL.PONE. 0197919

Tiwari, R., and Rana, C. S. (2015). Plant secondary metabolites: a review. Intern. J. Eng. Res. Gen. Sci. 3, 661-670. 
Triebl, A. (2016). “Glycerophosphocholines," in Encyclopedia of Lipidomics, ed. M. R. Wenk (Dordrecht: Springer), 1-2. doi: 10.1007/978-94-007-7864-1_33-1

Vašák, M., and Schnabl, J. (2016). Sodium and potassium ions in proteins and enzyme catalysis. Metal. Ions Life Sci. 16:259. doi: 10.1007/978-3-319-2175678

Wang, H., Zhang, S., Wang, X., and Lou, C. (2003). Role of acetylcholine on plant root-shoot signal transduction. Chin. Sci. Bull. 48, 570-573. doi: 10.1360/ 03tb9121

Wang, L., Xing, X., Chen, L., Yang, L., Su, X., Rabitz, H., et al. (2019). Peak annotation and verification engine for untargeted LC-MS metabolomics. Anal. Chem. 91, 1838-1846. doi: 10.1021/acs.analchem.8b03132

Wang, Y., Li, B., Du, M., Eneji, A. E., Wang, B., Duan, L., et al. (2012). Mechanism of phytohormone involvement in feedback regulation of cotton leaf senescence induced by potassium deficiency. J. Exp. Bot. 63, 5887-5901. doi: 10.1093/jxb/ ers 238

Webber, B. L., and Miller, R. E. (2008). Gynocardin from Baileyoxylon lanceolatum and a revision of cyanogenic glycosides in Achariaceae. Biochem. Syst. Ecol. 36, 545-553. doi: 10.1016/j.bse.2008.03.011

Wishart, D. S., Djoumbou, F. Y., Ana, M., Guo, A. C., Liang, K., Vázquez-Fresno, R., et al. (2017). HMDB 4.0: the human metabolome database for 2018. Nuclc Acids Res. 46, D608-D617. doi: 10.1093/nar/gkx1089

Wolf, M. A., Pant, R., Chomkhamsri, K., Sala, S., and Pennington, D. (2012). The international reference life cycle data system handbook. Instrument. Ence Technol. 43, 156-169. doi: 10.1080/10739149.2014.910670

Wu, C., Pullinen, I., Andres, S., Kiendler-Scharr, A., Kleist, E., Wahner, A., et al. (2017). 13C labelling study of constitutive and stress-induced terpenoide missions from Norway spruce and Scots pine. Biogeosci. Discuss. 260, 1-29. doi: 10.5194/bg-2017-260

Xu, X., Du, X., Wang, F., Sha, J., Chen, Q., Tian, G., et al. (2020). Effects of potassium levels on plant growth, accumulation and distribution of carbon, and nitrate metabolism in apple dwarf rootstock seedlings. Front. Plant Sci. 11:904. doi: $10.3389 /$ fpls.2020.00904

Yaglioglu, A. S., Temirturk, M., Ugur, E., Dolarslan, M., and Demirtas, I. (2020). Metabolomics of endemic six Astragalus species by combined NMR and GC-MS analysis. Phytochem. Anal. 31, 306-313. doi: 10.1002/pca. 2896

Yuningsih, Y. (2008). Cyanide Content and Stability in Picung Plant (Pangium edule Reinw.) And its Usage. Bogor: Badan Litbang Pertanian.

Zelinová, V., Mistrík, I., Pal'ove-Balang, P., and Tamás, L. (2010). Peroxidase activity against guaiacol, $\mathrm{NADH}$, chlorogenic acid, ferulic acid and coniferyl alcohol in root tips of Lotus japonicus and L. Corniculatus grown under low $\mathrm{pH}$ and aluminium stress. Biologia 65, 279-283. doi: 10.2478/s11756-010-0029-3

Zeng, J., Quan, X., He, X., Cai, S., Ye, Z., Chen, G., et al. (2018). Root and leaf metabolite profiles analysis reveals the adaptive strategies to low potassium stress in barley. BMC Plant Biol. 18:187. doi: 10.1186/s12870-018-1404-4

Zhang, L., Tian, L., Zhao, J., Song, Y., Zhang, C., Guo, Y., et al. (2008). Identification of an apoplastic protein involved in the initial phase of salt stress response in rice root by two-dimensional electrophoresis. Plant Physiol. 149, 916-928. doi: 10.1104/PP.108.131144

Zhang, X., Song, Z., Liu, T., Guo, L., and Li, X. (2016). De Novo assembly and comparative transcriptome analysis provide insight into lysine biosynthesis in Toona sinensis roem. Intern. J. Genom. 2016:6735209. doi: 10.1155/2016/ 6735209

Zhang, Z., Chao, M., Wang, S., Bu, J., Tang, J., Li, F., et al. (2016). Proteome quantification of cotton xylem sap suggests the mechanisms of potassiumdeficiency-induced changes in plant resistance to environmental stresses. Sci. Rep. 6:21060. doi: 10.1038/srep21060

Zhang, Z., Xin, W., Wang, S., Zhang, X., Dai, H., Sun, R., et al. (2015a). Xylem sap in cotton contains proteins that contribute to environmental stress response and cell wall development. Funct. Integrat. Genom. 15, 17-26. doi: 10.1007/s10142014-0395-y

Zhang, Z., Zhang, X., Hu, Z., Wang, S., Zhang, J., Wang, X., et al. (2015b). Lack of K-dependent oxidative stress in cotton roots following coronatine-induced ROS accumulation. PLoS One 10:e126476. doi: 10.1371/journal.pone.0126476

Zhao, S., He, P., Qiu, S., Jia, L., Liu, M., Jin, J., et al. (2014). Long-term effects of potassium fertilization and straw return on soil potassium levels and crop yields in north-central China. Field Crops Res. 169, 116-122. doi: 10.1016/j.fcr.2014. 09.017

Conflict of Interest: The authors declare that the research was conducted in the absence of any commercial or financial relationships that could be construed as a potential conflict of interest.

Copyright (c) 2020 Zhang, Wang, Xue, Zhang, Wang, Zhang and Zhang. This is an open-access article distributed under the terms of the Creative Commons Attribution License (CC BY). The use, distribution or reproduction in other forums is permitted, provided the original author(s) and the copyright owner(s) are credited and that the original publication in this journal is cited, in accordance with accepted academic practice. No use, distribution or reproduction is permitted which does not comply with these terms. 